\title{
How can I as a Māori music therapy student develop the use of taonga puoro in my practice to support client recovery in an inpatient mental health setting?
}

\author{
Ruby Mae Hinepunui Solly \\ An exegesis submitted to Victoria University of Wellington in partial fulfilment of the \\ requirements for the degree \\ Master of Music Therapy \\ Te Kōkī - New Zealand School of Music
}

2019 


\section{Abstract}

This research focuses on developing the use of taonga puoro as part of an individual's music therapy practice, within the context of an acute mental health unit. This was qualitative research guided by Kaupapa Māori Theory, using a self-reflective action research design of three cycles. Through the three action research cycles, themes were observed and developed within the secondary analysis of clinical notes and a reflective journal, with action plans created as a response. At the end of the three cycles, a model for using taonga puoro in music therapy, 'Nga Pou e Ono', was created by looking retrospectively at the cycles. This research acknowledges the importance of narrative, depth of topic, acknowledgement of self-determination, spirituality, personal power, and the environment within taonga puoro based music therapy. This research has been inspired by the works of other Māori and Indigenous music therapists such as Dennis Kahui (2008), Nolan Hodgson (2014), and Carolyn Kenny (1989), as well as acknowledging the traditions of taonga puoro for healing within Māori society, and the revivalists whose mahi aroha helped to further embed taonga puoro within te ao Māori. 
Tēnā tatou katoa

'E hara taku toa

i te toa takitahi,

he toa takitini'

Ko wai au?

Ko John Solly raua ko Jane Wildbore oku mātua

Ko Takitimu te waka

Ko Aoraki te mauka

Ko Hinepunui raua ko Te Kapa oku tūpuna

Ko Ngati Huirapa raua ko Ngāi Tūāhuriri oku hapū

Ko Rakahuri raua ko Wahao oku awa

Ko Waihao raua ko Tuahiwi oku marae

Ko Maahunui te tuarua te wharenui

Ko Kai Tahu te iwi

Ko Ruby Mae Hinepunui Solly tōku ikoa

This pepeha pays tribute to my ancestral grounds in Te Wai Pounamu, and to my tūpuna and whānau. I would like to thank those who have contributed so full heartedly to this kaupapa. As the whakatauki describes above "This is not the work of one, but the work of many". I would like to thank the taonga puoro community for their tautoko and aroha throughout this process, with special thanks to Alistair Fraser, Jerome Kavanaugh, Ariana Tikao and Sam Palmer. Alistair especially for your gentle guidance, support, and help, and to Sam for the beautiful koha of instruments that you donated to this project. Thanks also to Sarah Hoskyns, whose excitement and belief in te ao Māori inspires me to continue to share our perspective with the world of music therapy. Thanks to Vanessa Eldridge for your council, and helping me to see the strength within myself. Nga mihi kia koe Vini Olsen Reader, who assisted with the te reo Māori, and with solidifying my te ao Māori worldview. Arohanui to my family, some of whom have passed on during this journey. It is a true privilege to have gone through this work with my partner, Daniela Butterfield. Your unrelenting support of me and my mahi has been a continual source of strength for me, and I am forever grateful. But none of this work would have been possible, without the work of our tūpuna, who kept taonga puoro alive through history despite all obstacles, and to the revivalists, Melbourne, Flintoff and Nunns, and those who have come after them. 


\section{Contents}

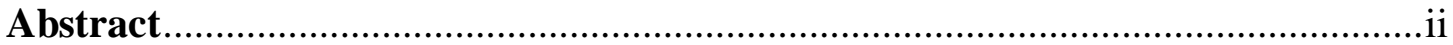

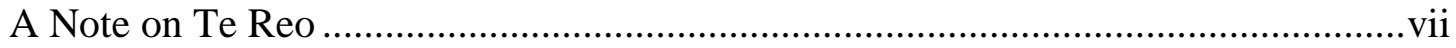

Glossary / Papakupu ….........................................................................................iii

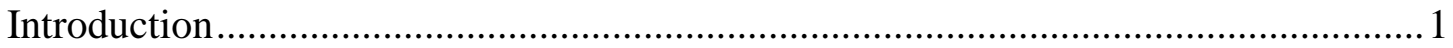

Māori Mental Health and Taonga Puoro .............................................................. 1

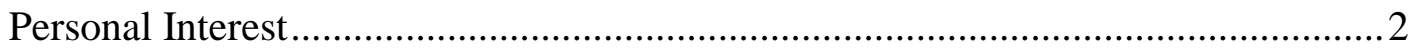

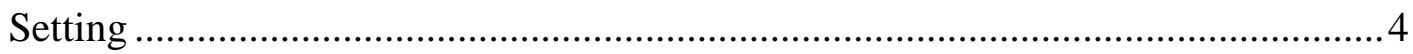

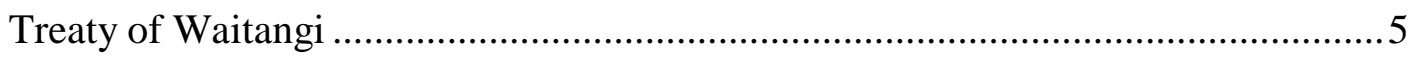

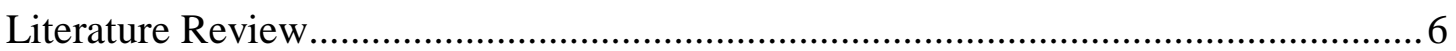

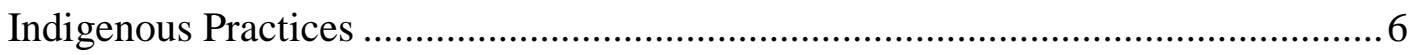

Deeper Connections with Music Therapy........................................................ 9

Therapeutic Applications of Taonga Puoro as described within the Literature........ 11

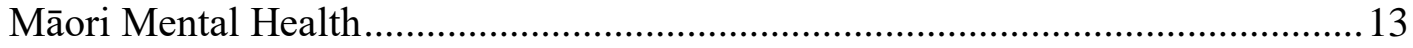

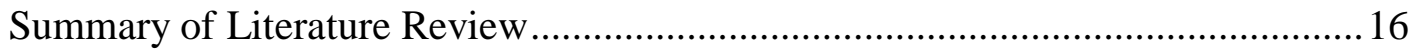

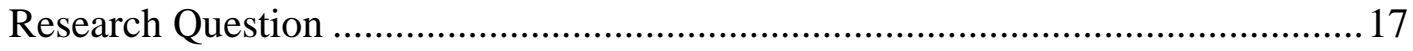

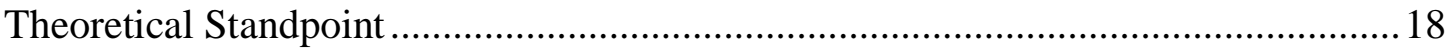

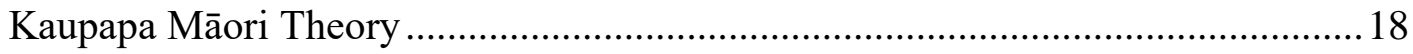

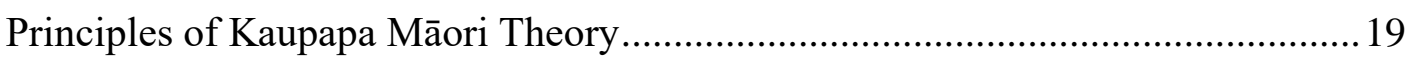

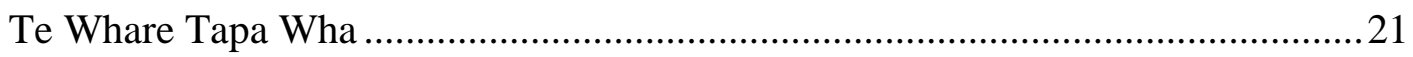

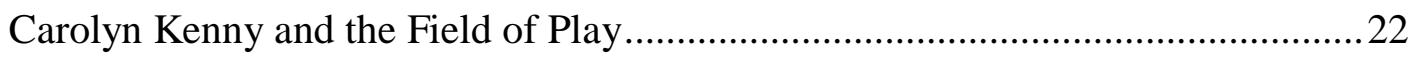

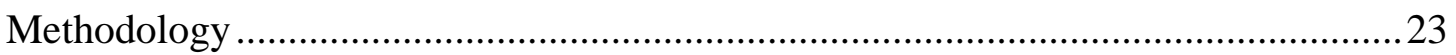

The Action Research Process.................................................................................23

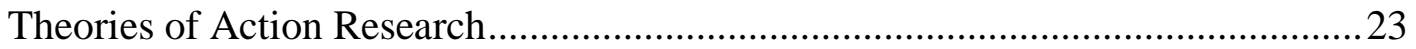

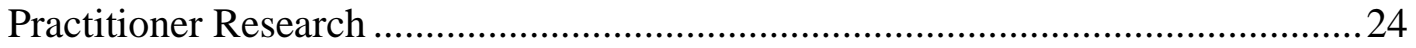

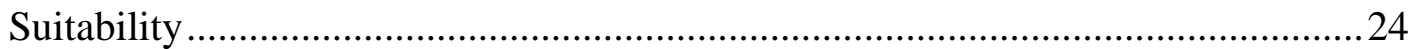

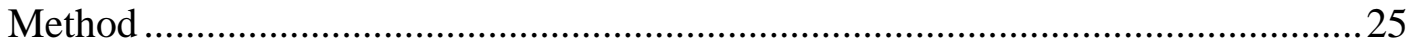




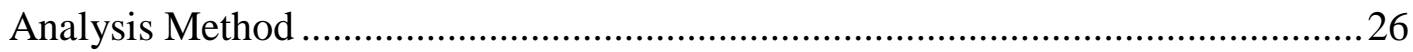

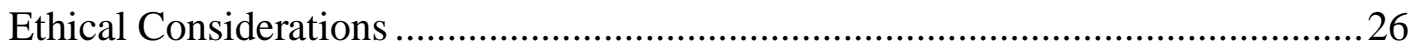

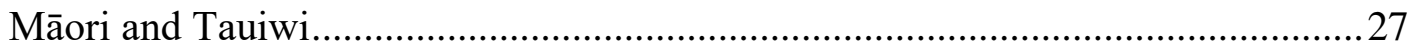

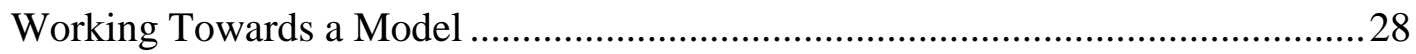

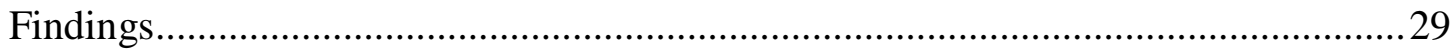

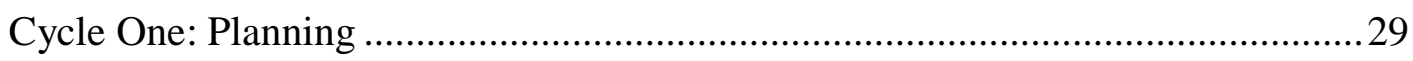

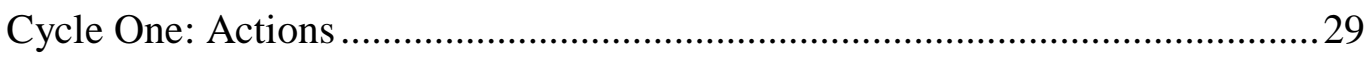

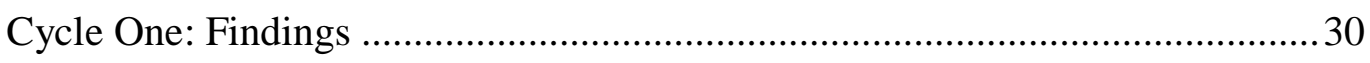

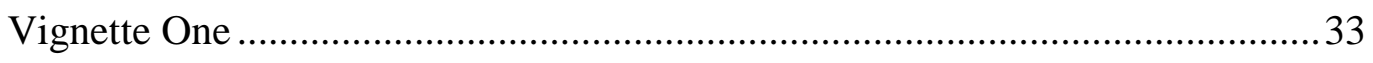

Cycle One: Conclusions and Preliminary Plans for Cycle Two .......................... 34

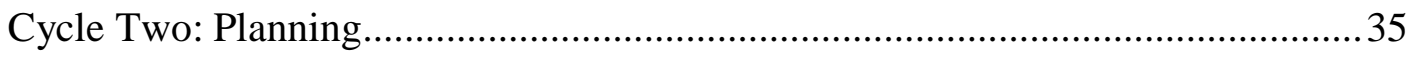

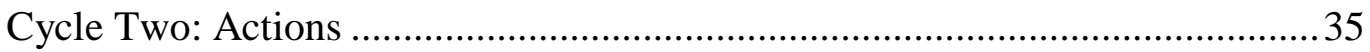

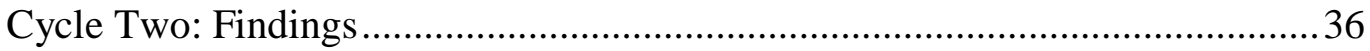

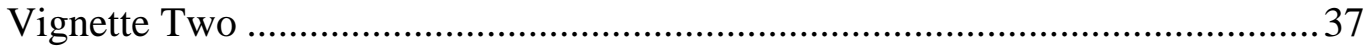

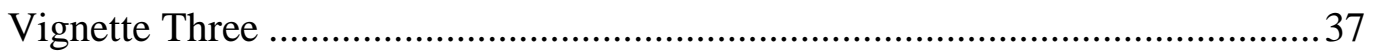

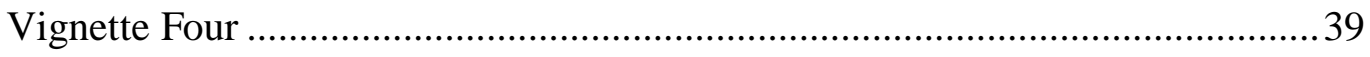

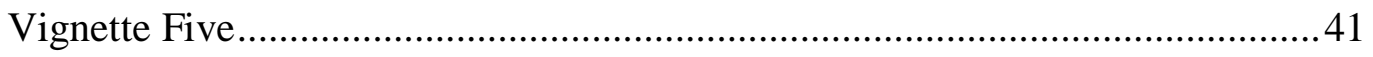

Cycle Two: Conclusions and Preliminary Plans for Cycle Three ......................43

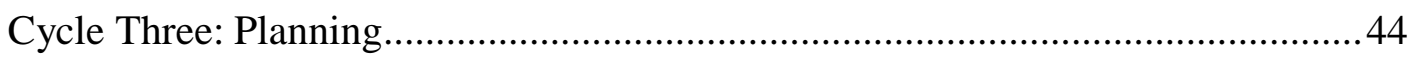

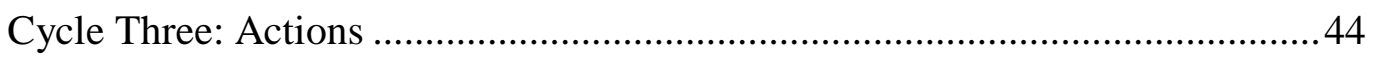

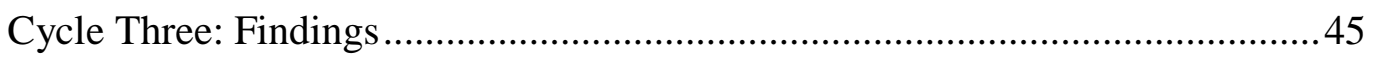

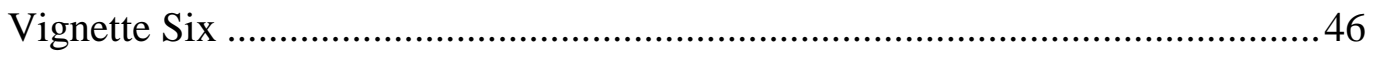

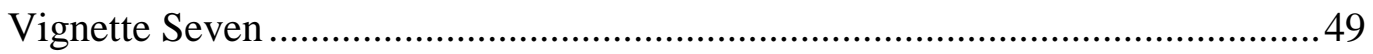

Cycle Three: Conclusions and Directions for Final Model of Practice ................52

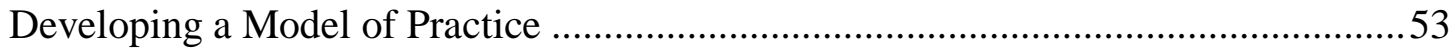

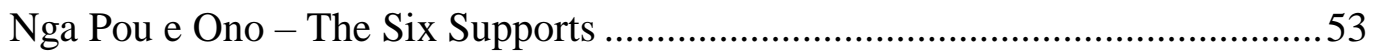

Te Pou Pakiwaitara - The Support of Narrative and Story Telling ….....................55 
Te Pou Rangatiratanga - The Support of Self-Determination .56

Te Pou Mana - The Support of Personal Power. .57

Te Pou Taiao - The Support of the Environment .............................................58

Te Pou Hōhonu - The Support of Depth ............................................................59

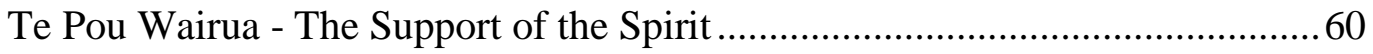

Te Kauwhanga Whakahaumanu - The Central Space of Rejuvenation and Therapy 61

Discussion 62

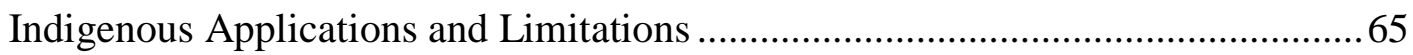

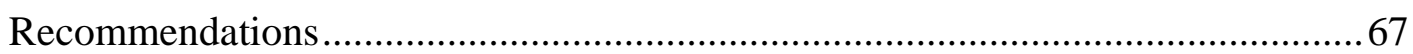

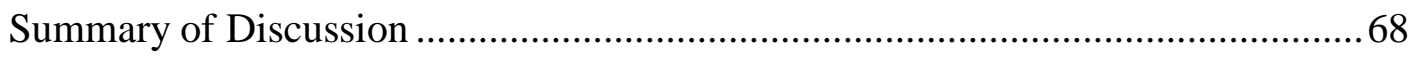

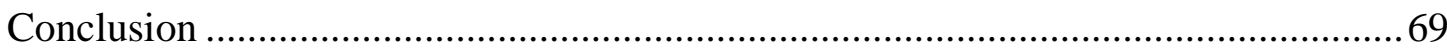

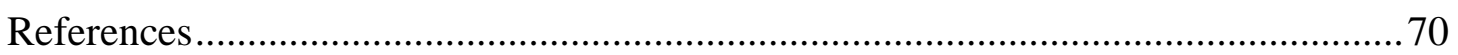

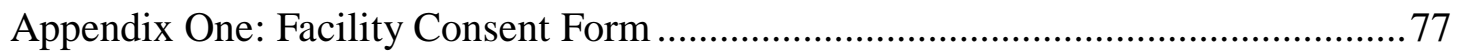

Appendix Two: Example of Reflective Journal....................................................... 79

Appendix Three: Cycle One Nvivo coding example ................................................. 83

Appendix Four: Example Diagram of Top Code with Sub Codes .............................. 84 


\section{A Note on Te Reo}

As this is a resource created by Māori, primarily for Māori, I have decided to use our own kupu throughout the work, explaining where appropriate. There is also a Papakupu or glossary following this section. It is often said that within te ao Māori that there are entire worlds within each word. For example, the syllable ' $p u$ ' can signify abundance, beginnings, grouping together, and other meanings depending on the context and word it is used in. I recommend delving deeper into te reo, to better understand the kupu used. 


\section{Glossary / Papakupu}

These translations were accessed from Te Aka Online Māori Dictionary accessed from https:www.maoridictionary.com, created by John Moorefield. Copyright $2003-2018$.

Aroha $=($ noun $)$ affection, sympathy, charity, compassion, love, empathy

Arohanui $=($ noun$)$ much love, with deep affection .

Atua $=($ noun $)$ ancestor with continuing influence, god, demon, supernatural being, deity, ghost, object of superstitious regard, strange being - although often translated as 'god' and now also used for the Christian God, this is a misconception of the real meaning. Many Māori trace their ancestry from atua in their whakapapa and they are regarded as ancestors with influence over particular domains. These atua also were a way of rationalising and perceiving the world. Normally invisible, atua may have visible representations.

Hapu $=$ (noun) kinship group, clan, tribe, subtribe - section of a large kinship group and the primary political unit in traditional Māori society. It consisted of a number of whānau sharing descent from a common ancestor, usually being named after the ancestor, but sometimes from an important event in the group's history. A number of related $h a p \bar{u}$ usually shared adjacent territories forming a looser tribal federation (iwi).

Hauora $=($ noun $)$ health, vigour .

Karakia $=($ noun $)$ incantation, ritual chant, chant, intoned incantation, charm, spell $-\mathrm{a}$ set form of words to state or make effective a ritual activity.

Karanga manu $=($ noun$)$ bird-calling flute

Kaumātua $=($ noun$)$ adult, elder, elderly man, elderly woman, old man - a person of status within the whānau. 
Kaupapa $=($ noun$)$ topic, policy, matter for discussion, plan, purpose, scheme, proposal, agenda, subject, programme, theme, issue, initiative.

Kōauau $=($ noun $)$ cross-blown flute - smaller than a pūtōrino, this instrument was traditionally made of wood, bone or a species of kelp. Most have three finger holes (wenewene), but some have none and others five or six.

Koha $=($ noun $)$ gift, present, offering, donation, contribution - especially one maintaining social relationships and has connotations of reciprocity.

Kōrero $=($ noun $)$ speech, narrative, story, news, account, discussion, conversation, discourse, statement, information

Mana $=($ noun $)$ prestige, authority, control, power, influence, status, spiritual power, charisma - mana is a supernatural force in a person, place or object.

Maramataka $=($ noun$)$ almanac, Māori lunar calendar, calendar - a planting and fishing monthly almanac.

Mauri $=($ noun $)$ life principle, life force, vital essence, special nature, a material symbol of a life principle, source of emotions - the essential quality and vitality of a being or entity.

Matariki $=($ personal noun $)$ Pleiades, Messier $45-$ an open cluster of many stars in Te Kāhui o Matariki, with at least nine stars visible to the naked eye.

Mātauranga $=($ noun$)$ knowledge, wisdom, understanding, skill.

Mihimihi $=($ noun $)$ speech of greeting, tribute - introductory speeches at the beginning of a gathering.

Mirimiri $=($ noun $)$ massage .

Nguru $=($ noun $)$ nose flute - short, semi-closed, cross-blown flute, with a curved end, 
made of wood, bone or stone and played with the mouth and nose.

Papatūānuku $=($ personal name $)$ Earth, Earth mother and wife of Rangi-nui - all living things originate from them.

Pepeha $=($ noun$)$ tribal saying, tribal motto, proverb (especially about a tribe), set form of words, formulaic expression, saying of the ancestors, figure of speech, motto, slogan - set sayings known for their economy of words and metaphor and encapsulating many Māori values and human characteristics.

Poroporoaki $=($ verb $)(-$ tia $)$ to take leave of, farewell.

Porotiti $=($ noun $)$ spinning disc, humming disc - disc with two holes through which a string is threaded and used to make the disc spin

Pou $=($ noun $)$ support, supporter, stalwart, mentor, symbol of support, metaphoric post - someone, a group, tribe, gathering or something that strongly supports a cause or is a territorial symbol, such as a mountain or landmark, representing that support.

Poi Awhiowhio $=($ noun $)$ whistling gourd - a small gourd with holes which is attached to a string and twirled to create a sound like that of birds. Sometimes as poiāwhiowhio.

Purerehua $=($ noun $)$ bullroarer - a traditional Māori musical instrument made of wood, stone or bone attached to a long string.

Pūtātara $=($ noun $)$ conch shell trumpet with an attached short, wooden mouthpiece.

Pūtorino $=($ noun $)$ large traditional flute - the largest of the traditional flutes, usually made of wood and played as a flute or trumpet and between 30 and $60 \mathrm{~cm}$ in length

Rākau $=($ noun $)$ tree, stick, timber, wood, spar, mast, plant

Raranga $=($ verb) $($ rangā,rānga) to weave, plait (mats, baskets, etc.) 
Romiromi $=($ verb) $(-$ a,-hia,-tia) to press firmly with the hands, squeeze, rub gently, massage.

Rangatahi $=($ noun $)$ younger generation, youth.

Ranginui $=($ personal name $)$ atua of the sky and husband of Papa-tū-ā-nuku, from which union originate all living things.

Rongoa $=($ noun $)$ remedy, medicine, drug, cure, medication, treatment, solution (to a problem), tonic.

Rōpū $=$ (noun) group, party of people, company, gang, association, entourage, committee, organisation, category.

Taiao $=($ noun$)$ world, Earth, natural world, environment, nature, country.

Takatāpui $=($ noun$)$ lesbian, gay, homosexual, gay men and women. (Note; outside of this definition from the Māori dictionary, Takatāpui also includes trans and gender diverse people)

Tangaroa $=$ (personal name) atua of the sea and fish, he was one of the offspring of Rangi-nui and Papa-tū-ā-nuku and fled to the sea when his parents were separated. Sometimes known as Tangaroa-whaiariki.

Tauiwi $=($ personal noun $)$ foreigner, European, non-Māori.

Taonga $=($ noun $)$ treasure, anything prized - applied to anything considered to be of value including socially or culturally valuable objects, resources, phenomenon, ideas and techniques

Tautoko $=($ verb) $(-$ hia,-na,-tia) to support, prop up, verify, advocate, accept (an invitation), agree. 
Taunga puoro $=($ noun $)$ musical instrument.

Te ao Māori = (noun) the Māori world.

Te ao Pākehā = (noun) the Pākehā world.

Te reo Māori = (noun) the Māori language.

Te wai pounamu $=$ (location) South Island

Tohunga $=$ (noun) skilled person, chosen expert, priest, healer - a person chosen by the agent of an atua and the tribe as a leader in a particular field because of signs indicating talent for a particular vocation.

Toi $=($ noun$)$ art, knowledge.

Tukutuku $=($ noun $)$ ornamental lattice-work - used particularly between carvings $\backslash$ around the walls of meeting houses.

Tumutumu $=($ noun $)$ beater, striker - ancient musical instrument made of stone or wood used to set rhythms for chanting.

Tūpuna $=($ noun $)$ ancestors.

Turangawaewae $=($ noun $)$ domicile, standing, place where one has the right to stand place where one has rights of residence and belonging through kinship and whakapapa.

Wāhine $=($ noun $)$ women, females, ladies, wives - plural form of wahine.

Waiata $=($ noun $)$ song, chant, psalm

Wairua $=($ noun $)$ spirit, soul - spirit of a person which exists beyond death. It is the non-physical spirit, distinct from the body and the mauri. 
Wenewene $=($ noun $)$ hole in a flute, finger hole

Whakairo $=($ noun $)$ carving.

Whakamā $=$ verb) to be ashamed, shy, bashful, embarrassed.

Whakaora $=($ verb $)(-$ tia,, hia,, -ngia $)$ to save, rescue, resuscitate, revive, restore to health, cure, heal, remedy.

Whakatauki $=($ noun $)$ proverb, significant saying, formulaic saying, cryptic saying, Aphorism.

Whakawhanaungatanga $=($ noun $)$ process of establishing relationships, relating well to others.

Whānau $=$ (noun) extended family, family group, a familiar term of address to a number of people - the primary economic unit of traditional Māori society. In the modern context the term is sometimes used to include friends who may not have any kinship ties to other members.

Whanaungatanga $=($ noun $)$ relationship, kinship, sense of family connection $-\mathrm{a}$ relationship through shared experiences and working together which provides people with a sense of belonging. It develops as a result of kinship rights and obligations, which also serve to strengthen each member of the kin group. It also extends to others to whom one develops a close familial, friendship or reciprocal relationship.

Whariki $=($ noun $)$ floor covering, ground cover, floor mat, carpet, mat 


\section{Introduction}

\section{Māori Mental Health and Taonga Puoro}

In traditional Māori society, it was common practice to go to a tohunga when experiencing physical or mental health issues (Rollo, 2013). Tohunga were persons of high esteem and knowledge who would use various methods including mirimiri and romiromi, karakia, and taonga puoro. Taonga puoro were not only used by tohunga but were also used by Māori as personal tools of healing, ritual and communication (Best, 1925). The introduction of the Tohunga Suppresion Act of 1906 limited the use of these instruments and they were hidden until the end of the century (Robinson, 2005). Beginning in the 1970s, Hirini Melbourne and Richard Nunns travelled around Aotearoa playing the instruments and gathering knowledge from kaumatua (Flintoff, 2004). These men along with maker Brian Flintoff, and many others, helped to revitalize taonga puoro in Aotearoa both for performance and healing, as a mahi aroha both for Māori and as an act of decolonization.

In post war New Zealand, Māori mental health issues have increased dramatically with depression having a 7.6 percent increase in the population within the last decade, as well as other increases within mental illnesses such as bipolar, anxiety disorders, and personality disorders according to diagnostic information from the Ministry of Health 2016 health survey (Ministry of Health, 2016). Some attribute these radical changes in numbers to long term effects of urbanization, also known as the "second migration"; where circumstances beyond their control caused many Māori to move away from traditional, rural based life styles, and travel away from hapu based living to cities in search of better opportunities for their whānau (Kingi, 2011). Prior to the second migration, Māori rates of mental health issues were perceived to be much lower than Pākehā, according to Beaglehole; "The fact that there are fewer neurotic and psychotic illness among Māori than among Pakehas in New Zealand emphasizes among other things the tremendous value to the Mãori of possessing a psychological security that comes from tribal and family security" (1947, p.243). 


\section{Personal Interest}

As a Māori music therapy student, I feel that the way I conduct therapy both with Māori and Tauiwi (non-Māori) clients is influenced by my cultural and ethnic background. I was raised in an environment where both Pākehā and Māori music were present and interchangeable. However, outside of the comfort zone of my own music, things didn't feel so fluid. When playing cello in orchestras, I felt like something about me didn't fit in. I moved too much when playing, I didn't look like the other players, I didn't respond to music in the same way, and to my childhood self it felt like everyone was on the verge of finding out that I wasn't supposed to be there.

Unfortunately, I felt a similar way in te ao Māori. I wasn't naturally gifted at Kapa Haka, and often assisting by singing and playing guitar. But my ties with Western music always made me seem different as a lot of my musical interests came from the classical tradition, and were not the same as that of my peers. I felt like this wasn't the right space for me either.

It was a teacher at primary school who introduced me to the kōauau. I remember being able to get a few notes from the instrument and the feelings of peace and centeredness that this brought me. I have a memory of being told by another adult at the school that kōauau was not for girls to play, and for a while my journey with taonga puoro was held in waiting. When I started my Masters, I began to investigate music and its abilities to help and heal. However, again I felt like this was a world where I was struggling to fit. During one of my papers, I was prompted to investigate taonga puoro. I talked to a range of players (who would later become my mentors) and discovered a range of musicians, Māori, Pākehā, male, female; coming together to use these instruments to decolonize, educate, and in many cases; to heal. It was then that I came to the realisation that it was my place to use these taonga as much as it was my place to work as a music therapist. All along, my biggest struggle had been my biggest strength; I was able to walk in both te ao Māori, and in te ao Pākehā.

I began using the taonga at my placements, gradually incorporating the instruments until they became a normal part of practice with both Māori and Tauiwi clients. I noticed the instruments had a wide range of applications for therapy; from increasing cultural 
connections, to breath control; teaching conversational norms, to mastery, and all things inbetween. I feel that my practice is more diverse and serves both Māori and Tauiwi better for having taonga puoro at its' heart, and I feel a strong desire to see how I can use taonga puoro as a music therapist to promote Tino Rangatiratanga, decolonize, and to walk better in both worlds to which I belong. I believe that Māori being able to access and choose to be treated with therapies from te ao Māori is a way that both Māori clinicians and patients can work towards decolonization of the health care system, and is a way for us to exercise our right to Tino Rangatiratanga.

\section{He Mokopuna He Tūpuna}

Taonga puoro has been a part of rongoa Māori since the time of our tūpuna, with taonga puoro being crucial to wellbeing, healing, ceremonies, birth and death (Best, 1925)(Nunns, 2001). Within my engagement with taonga puoro in music therapy, I am not aiming to repurpose or recreate something that is already whole and true. My wish is to be able to weave together our own therapy with Western music therapy to make music therapy more accessible for our people, and to share our own valid and important methods of healing with those who need them. When I think of te ao Māori, I think of a world where music and healing are done with the same breath; te ha. Before engaging with taonga puoro within my music therapy practice I consulted with rongoa practitioners, taonga puoro experts, Māori sound healers and kaumatua in order to engage with the knowledge that has been passed down to us through whakapapa. Renowned sound healer Jerome Kavanagh (Ngāti Kahununu) spoke to me about his work, and how his tūpuna give him strength and knowledge as a healer. Jerome shared with me that this work and how to do it is within our whakapapa as Māori - it is a part of our DNA. When I think of the first experiences I had with playing as a child. I think of how it felt to connect with taonga puoro and the deep feelings of calm and connectedness that brought me. I also think of the incredible work that rongoa Māori practitioners and healers do for our people, knowledge that has been passed on and built up for centuries. When I go into my work in music therapy, I use my instincts as well as all I have learnt through my training, giving both equal validity within the therapy room. As within academia, within taonga puoro and its ways of healing, I too aim to stand on the shoulders of giants. 


\section{Setting}

My placement was based at an inpatient psychiatric unit within a hospital setting. The unit is comprised of two main wings; a lower security and a medium security, with deescalation rooms attached. The facility contains client focused features such as outdoor herb gardens, a women's space, TV room, gym, large open plan lounge / dining area, library, music room, and sensory room. Client safety and rites are paramount in the unit and to assist with this the facility has a secure office space containing meticulously kept files, a courtroom, meeting rooms, and nurses' stations in each wing.

The client base consists of people who need both acute and more long-term care, with some clients being at the facility for ten months or more. The facility caters to a wide range of clients including those with depression, schizophrenia, bi-polar disorder, obsessive compulsive disorder, post-traumatic stress disorder, and some patients with complex diagnosis that may include eating disorders.

The unit has a large team including nurses, social workers, occupational therapists and assistants, doctors, psychiatrists, office staff, and a house surgeon. Staff are dressed in plain clothes and work in two teams to ensure client needs are met. Clients are invited to participate in a wide variety of therapeutic activities, outings, and group work including music therapy, meditation, coffee groups, CBT group therapy, writing groups, community walks and coaching in the facility's gym. Participation is in most cases voluntary for the clients, thought they are encouraged to attend therapy sessions and their participation is recorded in their notes. Staff in the unit work in conjunction with teams in the community including community mental health services, as well as with other inpatient services to assist with patients' possibly transitioning to different facilities throughout the course of their treatment.

The unit utilizes Mason Durie's 'Te Whare Tapa Whà' (1994) which has a strong influence on wellbeing,. 'Te Whare Tapa Wha' is a model of health based of the four walls of a wharenui, focusing on the body, mind, spirit and family as focus areas of health; this model will be explained more fully in chapter three. The facility also has a resident kaumātua who assists with the cultural wellbeing and hauora of clients and staff. Staff begin morning 
meeting each day with waiata and karakia. These elements are further incorporated into group meetings with clients, and elements of Māori culture are included throughout activities within the unit as well as working with the Treaty of Waitangi in all areas of practice.

\section{Treaty of Waitangi}

For those outside of Aotearoa, I will briefly explain the Treaty of Waitangi and its importance to research. The Treaty of Waitangi has been described as New Zealand's founding document, written and signed in 1840, it is a document outlining conditions between Pākeha and Māori in New Zealand. The document is controversial for many Māori for a range of issues including poor translation and poor adherence by the crown (Orange, 2015).

In terms of research, in 1988 the Royal Commission on Society Policy identified the Treaty principles of partnership, participation and protection, helping to bring the treaty into research ethics and contemporary New Zealand society as a whole (Durie, 1994). These principles put relationships at the core of research with Māori, which is promoted by Indigenous academics such as Hudson (2004), and Powick (2002). These principles highlight the fact that the state has a responsibility to recognise the rite of Māori to tino rangatiratanga, as well as to protect Māori interests. The Treaty of Waitangi is recognised as a critical part of our ethical framework, and aims to highlight and reflect the ethics of both of its parties; Māori and Pākehā (Hudson \& Russell, 2009). 


\section{Literature Review}

I have decided to break this review into four sections for purpose of clarity, and to make sure that I have enough literature on taonga puoro and its therapeutic applications for Māori mental health, and Indigenous music therapy with a focus on Māori. For finding materials, I used the Victoria University search engine, 'Te Waharoa', with the terms 'taonga puoro' and 'music therapy', 'Māori mental health' and 'taonga puoro' 'Indigenous music therapy', 'māori music therapy', 'taongo puoro' and 'healing', and Indigenous music therapy' I also found sources from recommendations from fellow group members of 'Matapikitia Ngā Taonga Puoro', a taonga puoro group from which I received much support throughout this project.

\section{Indigenous Practices}

I feel it is important to note my views on preconceptions around the word Indigenous. It is believed that there are over 370 million Indigenous people in the world, from over 5000 ethnic groups (Horton, 2006). In the literature, there is a trend to compare different Indigenous groups and at times to relate certain results from one ethnic group to others. I believe that Indigenous groups are not as homogenous as they are often described within the literature; however, similarities between the groups have been well documented and investigated. For example, many Indigenous groups have strong ecological relationships with nature. But this doesn't mean that all 5000 plus groups will have this attribute, or that each group will perceive the relationship the same way. I have attempted to locate sources on music therapy that are either directly about Māori, or from groups that I believe share a similar world view to Māori such as Native American groups as researched by Native American music therapist and scholar, the late Professor Carolyn Kenny.

Millicent McIvor was a pioneer in intersectional research between music therapy and te ao Māori, which can be seen in two of her articles for The Annual Journal of the New Zealand Society for Music Therapy (1988, 1998). In her earlier article, McIvor explored the realm of traditional Māori music and chants, exploring both their intended purposes within the culture, and the wider therapeutic values that have relevance within music therapy. These 
included strengthening and forming group solidarity, identity formation and the strengthening of self worth, emotional release, and the enhancement of physical, mental, and spiritual wellbeing. McIvor also acknowledges that though puoro Māori is listened to as "pieces of music", this doesn't correctly identify the functions and nuances of puoro, perhaps one of the many reasons that early Pākehā failed to understand Māori music upon first contact. McIvor also describes several historical ways that taonga puoro were played, including the speaking of words or poetry into the putorino. In her 1998 article, McIvor worked with a group of kaumatua using Guided Imagery and Music (GIM). She found similar themes throughout the group including whakapapa, connection to whanau, the natural environment, and atua Māori. Themes around the tohunga suppresion act were also noted in one participant, showing the wide impact of the act on Māori both within the conscious and sub-conscious mind.

Fletcher, Green, MacDonald, and Hoskyns (2014) incorporated elements of kaupapa Māori including taonga puoro into a collaborative cultural project in an infant and adolescent mental health service. This article discussed the use of both weaving and taonga puoro with clients. In both cases, clients were taught tikanga Māori about how to weave and where the instruments came from. The knowledge of the clients was incorporated into the sessions in a non-hierarchical way, with a client working with taonga puoro describing the purerehua as sounding "like death". It was then discovered by the music therapist that the purerehua is believed to communicate desires to our tupuna, meaning that the client's instinctive knowledge was right. The taonga was also used to assist with family music therapy, in which the client who experienced Attention Deficit and Hyperactivity Disorder (ADHD) was able to demonstrate his mastery of the purerehua to his family, enabling them to see him in a positive light and to learn from the knowledge that he has, both musical and cultural.

Another project involving kaupapa Māori and mental health is Nolan Hodgson's 2014 thesis on using kaupapa Māori health models in an adolescent mental health unit. This research drew on Carolyn Kenny's 'Theory of Play' model, Durie's 'Te Whare Tapa Whà' model, Pere's 'Te Wheke' model and kaupapa Māori theory to incorporate kaupapa Māori elements such as mana, wairua, mauri, and non-verbal communication into Hodgson's practice. Hodgson found Pere's model to be most effective, as well as finding that many kaupapa Māori principles such as the concept of whakamā , wairua and 
whanaungatanga were all present within the facility. By utilizing kaupapa Māori resources such as waiata and rākau, Hodgson was able to engage both Māori and Tauiwi rangatahi in activities that promoted whanaungatanga, built mana, nourished wairua, and helped assist with grounding and recovery.

Another thesis that works with kaupapa Māori in music therapy is that by Dennis Kahui (2008). Kahui also utilized Te Whare Tapa Whā, in this case it was used as an assessment tool in an adolescent mental health context. Kahui worked with community centered music therapy principles, as well as a kaupapa Māori approach to promote recovery and cultural connectedness. Kahui also acknowledges the bitter taste of colonialism, and the ongoing affects that this has on the health of Māori today; "The injustices from the past have far reaching effects on the socioeconomic class of Māori in the present" (2008, p.18). Kahui also acknowledges the need to meet people where they are both in terms of music, and in terms of cultural knowledge, commenting on needing strong cultural support from kaumātua. In his background research findings, Kahui supports the use of action research as a highly relevant form of research involving Indigenous peoples.

It would be impossible to discuss Indigenous music therapy without mentioning Carolyn Kenny's substantial contribution to theory-building in the field. A large body of her work is relevant to this study, including her book 'The Field of Play: An Ecology of Being in Music Therapy' (1989) and an article of the same name that was featured in Voices: A World Forum for Music Therapy (2014). Kenny is a Native American music therapist who is the creator of the 'Theory of Play'; a music therapy theory that has influenced much of both Indigenous and western music therapy practice (Edwards, 2016). The 'Theory of Play' promotes ideas of non-hierarchical connections, ecology, beauty, and 'being' within music, as is in line with Native American, and many other Indigenous values. Kenny discusses the creation of her theory in this article, which includes explanations of the three main elements of her theory (aesthetics, and musical space, which intersect to become the third main element which is 'The Field of Play') and the four secondary elements (ritual, consciousness, power, and creative process). Kenny acknowledges the connection that many Indigenous peoples have with the natural world, something that I identify with as Māori. She speaks of having an awareness of the interplay and flux between all things and acknowledges the need to focus on personal aesthetics of clients in order to create a musical space. Kenny acknowledges her experiences as a Native American music therapist and describes three 
important aspects of her culture that she has also found within music therapy; ceremony, ritual, and play. She emphasises the importance of creating a ceremonial attitude going into a music therapy session and waiting for rituals to emerge. In an introduction written for an interview with Tina Fraser for Voices: A World Forum for Music Therapy (Elwafi, 2008), Kenny says "The Māori people have been one of the great inspirations in my own life... I came to know the Māori as people of great intelligence, generosity, creativity and affection. Their land, Aotearoa, is a place of intense beauty, and their many performing arts always begin by locating a Māori in his/her home territory. There is much to learn from this exciting culture". Kenny's interest in Māori culture and our use of music for ceremony, passing down of ancestral knowledge, and healing affirms the value that her work has within my practice and research. Kenny's very significant contribution to music therapy theory highlighting Indigenous insights and commitment to social justice, was acknowledged in a special tribute issue in her memory (following her death in 2017) of the international journal Voices: A World Forum for Music Therapy, Vol 18 No 3, in 2018.

\section{Deeper Connections with Music Therapy}

Aside from looking at Indigenous music therapy, I have been advised to investigate connections between natural Māori therapeutic techniques and ways of being, and approaches found in modern music therapy. There are five universally acknowledged music therapy approaches that were noted at the 1999 World Congress of Music Therapy. These included Analytical Music Therapy, Behavioural Music Therapy, Benenzon Music Therapy, Creative Music Therapy, and Guided Imagery and Music (Bunt and Hoskyns, 2002). In a modern context, Community Music Therapy is also a well known approach as well as Humanism and Humanistic Music Therapy. I will give more detailed explanations of the approaches most relevant to this work including Humanistic Music Therapy, Community Music Therapy and Analytical Music Therapy within this section.

Taonga puoro in music therapy can be compared to elements from humanistic philosophy which underpins and relates to a number of theoretical frameworks in music therapy including Creative Music Therapy, Free Improvsation Therapy, Humanism, and Humanistic Music Therapy. Humanistic philosophy utilises the concept that humans are whole beings, rather than just a combination of their parts or traits. The therapy also has the 
perspective that all clients have agency and the capacity of acting or exerting power, not subjects to be acted upon, but as subjects who act (Bugental, 1964). This can be related back to the concepts of mana or tino rangatiratanga, as well as the treaty principles of both partnership and participation. An important concept within HMT is that of 'being with', the idea of supporting a client and implying that to treat a client is to treat the client's individual humanity, and through that to treat humanity itself (Heidegger, 1962). This can be related back to taonga puoro being used to heal both the individual and the communities they are from as an act of decolonisation, as was reported by Nunns (2001).

Community Music Therapy (CoMT) features many elements that can be found within te ao Māori, and within the practice of taonga pūoro, as well as many shared values. CoMT is a resource-orientated therapy style that acknowledges that those in positions of disadvantage are deemed to be so as a product of both marginalisation and discrimination, and seeks to address this with inclusion and resourcing within the communities themselves (Stige, 2012). This can be related to Kaupapa Māori Theory where research works with Māori to enhance outcomes (Smith, 2005), as well as with all three principles of the Treaty of Waitangi; partnership, participation, and protection (Orange, 2015). The defining qualities of CoMT can be found in the mnemonic PREPARE which stands for participatory, resource-orientated, ecological, activist, reflective, and ethics-driven (Aaro \& Stige, 2011). Through these qualities, CoMT values the contributions of its participants, and seeks to redistribute social, material, and cultural resources. Valuing participant contribution and forming strong clienttherapist relationship was reported as important for success with Māori in health within the literature including that by Cram, Smith \& Johnstone (2003), and Kingi (2011).

Music therapy also values the use of music to process and release deeper emotions such is found within the techniques of Analytical Music Therapy (AMT) which include free association and holding, both of which are similar to those cited by Nunns and Thomas when describing taonga puoro as sung poetry that heightens the voice (Priestley, 1994; Thomas, 2011). Within his Master's thesis on the kōauau, Joél Kōmene speaks about his first time playing a pounamu kōauau which released floods of tears and emotion, helping him to process the death of a close loved one, which can again be related back to free association and patterns of significance, another technique used in AMT (Komene, 2009;Priestley, 1994). 


\section{Therapeutic Applications of Taonga Puoro as described within the}

\section{Literature}

I will begin this section by referring to a book / CD from acclaimed Māori scholar, writer, composer, taonga puoro player and revivalist, Dr Hirini Melbourne.

'Toiapiapi' (Melbourne, 1991) was released as a result of the knowledge that was regained from the work of Melbourne and Richard Nunns after they travelled around Aotearoa learning about the instruments and their applications from kaumātua. The work was described as a mahi aroha (work of love) for the Māori community restoring some of what they had lost through colonization and with that, the Tohunga Suppression Act of 1907 (New Zealand Legal Information Institute, 2019). The project serves both as an artistic work, and as an educational tool to teach Māori about our traditional instruments through Melbourne's lyrics, and descriptions within the book. Melbourne also describes his involvement with the creation of Houmanu groups; community based groups of taonga puoro players and enthusiasts. The purpose of these groups was to foster the use of taonga puoro within our communities and there are still groups today that meet regularly, though a lot are somewhat sporadic. In the introduction to the book, Richard Nunns describes the lack of acknowledgment of taonga puoro within the canon of Māori music, and describes how the instruments primary functions were for healing, ritual and ceremony; "[...] little recognition is given to the instrumental tradition - one which was developed as that of any Indigenous people. This tradition had both a variety of musical instruments and a profound and coherent function in community ritual and activity, for example, in birth, in healing, in making things grow, and in ushering people from this world" (1991, p.24). Both Nunns and Melbourne are inspiring advocates for the use of taonga puoro to heal both individuals and Māori as a people.

These applications are explored again in Allan Thomas' book 'World Music is Where We Found It' (2011) in a chapter he co-wrote with Nunns. Thomas and Nunns comment on how Māori saw waiata as being centered on poetry, and that waiata were "the musical word". They add that Māori also made this observation about their instrumental work, using taonga puoro to express themselves and heighten the voice. A point that relates well to music therapy principles, is how the musical domains of Māori were not restricted to 'musical' sounds, but were rather expressions of emotions, and needs. This relates to client- 
centered music therapy, where we can interpret everything the client does as being musical, allowing us to make all sound a part of their aesthetics and their music therapy experience.

A more general understanding of Māori healing and worldview can be gained from Te Manaaroha Pirihira Rollo's article 'Mā Te Wai Ka Piki Te Hauora' (2013) where the author explores how Māori healing, with an emphasis on sound healing, can benefit both Māori and Pākehā. Rollo discusses how Māori believe that we all have mauri, a spiritual energy, given to us by the creator, Io. Historically, as we were (and are) a tribal people, wellbeing and good health was crucial to our survival. Tohunga treated health concerns with a variety of mediums including taonga puoro and karakia; a crucial element to open up the body so that the tohunga could work. Rollo acknowledges the long-term effects that the Tohunga Suppression Act had on Māori healing, giving further detail regarding the resurgence in Māori healing during the 1980s after the act was revoked. The revival of Māori healing has led to the development of 'Ngā Ringa Whakahaere o Te Iwi Māori'; a national board of Māori healers. Rollo describes how using Māori instruments and methods in therapy not only serves to heal the individual, but also to decolonize and heal Māori as a whole via the revival and sustaining of our cultural practices. Rollo shares that at Raukatauri Music Therapy Centre in Auckland, taonga puoro including kōauau and pūtorino are used within their practice.

In an article for music therapy journal 'Voices' (2001), Richard Nunns describes his journey with taonga puoro and how the music has helped to heal. Nunns describes the oral tradition of Māori and recommends a need for therapists to seek information on kaupapa Māori and taonga puoro from Māori themselves first. He comments of his time spent travelling Aotearoa documenting how these taonga were used; "[...] these taonga, and the uses, the functions that they had, and the purposes that they were put to, bear virtually no relationship to entertainment as we understand it, and everything to do with matters to do with the wairua[...]", a kōrero that is truly in line with what has been said by Thomas, Melbourne and Rollo. Nunns speaks of the use of taonga as a form of Tino Rangatiratanga, or decolonization and self-governance, for Māori in terms of having our own therapies used for our own wellbeing, but also for the continuation and nurturing of ancestral knowledge. A concerning point about taonga puoro returning to the canon of Māori music is that the original therapeutic application of these instruments could be forgotten. According to Nunns; "In different areas, for instance, one hears of the kōauau being used to heal a broken 
bone, played in a particular way, or to help conception, or to promote the growth of plants, or to ease labor. Each of these functions dictated a different playing style, including one where the player vocalises and plays at the same time. There is some danger that, with the kōauau now being heard in the public media, these special applications and usages will recede even further." In terms of their use in music therapy, Nunns' words encourage us to take caution to honor ancestral uses of the instruments when using them to work with wairua. Through this article Nunns tells insightful anecdotes about his involvement with the taonga, including a story about playing to a river in Te Waipounamu at the request of local kaumātua, encouraging the river to heal. This idea that taonga puoro not only heal on an individual scale, but also work with the natural world to help us reconnect and heal the whenua and with that our people, is a strong one to take forward into the therapy room.

\section{Māori Mental Health}

In 'Māori Mental Health Needs Profile: A Review of the Evidence' (2008) Baxter outlines statistics of Māori health and District Health Board (DHB) goals for positive change in Māori health statistics. This survey found that Māori health statistics are overall far worse than their Pākehā counterparts, findings were attributed to a wide range of reasons including socio-economic deprivation, complicated accesses to support, negative conceptions about the health system, and urbanization. Baxter notes rising concerns for Māori mental health throughout the 1970s, 80s and 90s, into the $21^{\text {st }}$ century. He also found that Māori in rural areas and small towns had lower rates of mental health issues, whereas Māori in city environments had the highest rates. Baxter noted that over half of Māori would suffer from at least one mental illness in their lifetime and advocated for more targeted mental health treatment, policy changes, and a public emphasis on Māori well-being.

If we think about what Māori in rural areas possess that city dwellers may not, we may think of connection with whānau, hapū and iwi, and connection with nature. In their book 'Collaborative and Indigenous Mental Health Therapy: Tataihono - Stories of Māori Healing and Psychiatry'(2016), Wiremu NiaNia, Alistair Bush, and David Epston explain that to them, indigeneity is about the interconnectedness between all people and all things, a belief shared by Carolyn Kenny in her work 'The Field of Play' (1989). Bush discusses how 
we as Māori are interconnected through our whakapapa, which we all trace back to Ranginui and Papatūannuku; the sky father and earth mother. The authors show evidence of the value of being able to provide Māori mental health clients with contexts for their symptoms both in te ao Pākehā and te ao Māori. They speak of the value of Māori therapists working with Māori clients as a way to honor tradition and decolonize; and show evidence of Māori being more likely to seek help from Māori than from Pākehā. The authors discuss the sense of collective identity found within Māori culture where the sense of self is developed through our connections with people, and whenua, which is vastly different to how identity is perceived in many Pākehā frameworks. The authors describe how Māori originally means 'natural' and elaborate on the strong connection and strength that Māori receive from the natural world and the many taonga that she provides us with; many of which are used in the creation of taonga puoro.

It is important for us to know how Māori perceive their treatment and experiences in mental health services. Cram, Smith and Johnstone (2003) investigated the views of Māori receiving health services in 'Mapping the Themes of Māori Talk About Health', finding that wairua was the most frequently mentioned concept and that issues pertaining to a person's wairua were believed to be a leading cause of health issues. Wairua is a difficult concept to translate into English, but one could say it is the spiritual energy that is possessed by places, objects, people and things within the natural world (Patterson, 1994). As Māori, we know that when the wairua has not been correctly looked after, the health suffers. Wairua could also be described in some respects as wellbeing, though there is no complete translation for how we feel this term in Māoridom. In connection with the concept of wairua, this survey found that Māori were more likely to perceive health as a holistic concept, and often felt that Pākehā health workers were more inclined to treat symptoms rather than identify the root source of a problem. In this way Pākehā were seen to treat the illness rather than to work with the wairua of the patient. As in both Kahui and Hodgson's reports, this survey found that kaumātua approval and support was essential for all health professionals who are treating Māori, despite the ethnicity of health professionals. It was found that some Māori believed that the current health issues in their community could be traced back to the second migration of the 1950s. Overall, Māori had negative views around Pākehā health professionals and stated that it was easier for them to trust Māori health professionals. The ability to build rapport was a highly valued skill in terms of health care workers, which many Māori described as helping to ease their feelings of whakamā. Colonization was also 
discussed in this report in connection with the second migration and the removal of Māori from tribal lands, loosing this connection has had a negative effect on wairua as well as generational trauma and a loss of cultural resources.

Te Tani R. Kingi (2011) also discusses the effects of colonization and the second migration on Māori mental health in his chapter for 'Māori and Social Issues'. He notes the difficulties in plotting the changes that Māori mental health has taken over time as a result of a lack of statistics and written knowledge pre-colonization, adding that the data collected has been vague at best and is often captured through a Pākehā lens. Kingi also reports that historically when suffering from mental illness, Māori would seek treatment from a tohunga. Early immigrant writers reported a lack of mental illness in Māori society, however some songs and myths contain mentions of suicide, depression and other mental illness. Like Cram, Smith and Johnstone, Kingi suggests that urbanization and the second migration could be a cause of declining Māori mental health from the 1950s onwards, referencing Beaglehole's take on the issue that emphasizes the value of tribal and family security in Māori health care outcomes (Beaglehole, 1947). He refers again the lack of accuracy in statistics from this period, acknowledging that many Māori cared for those with illnesses within their own communities without needing to engage with public health care services prior to the second migration.

Like Cram, Smith and Johnstone (2003), Bowden acknowledges the importance of seeking guidance from kaumatua within his practice, providing his view on treating Māori as a Pākeha clinician. In his article 'Culturally-based impacts on a psychotherapy practice in Aotearoa' (2015), Bowden comments on how Māori focus less on the self than Pākehā, and more on their connections. He discusses the value of grounding clients by engaging with tupuna (ancestors) and ancestral lands, describing these connections as more important than the issue the client is facing and emphasises the value of these connections for Māori mental health. Bowden acknowledges the need to build rapport with Māori clients, and that in Māoridom you are expected to share more of yourself as a healer than you are in Pākehā society, a therapeutic view that is shared by Niania, Bush, Epston (2016), citing ??the historically reflective work of Kingi (2011). He writes on how his journey into tikanga Māori has led created changes in his therapeutic practice, not just for Māori, but for all his clients; "Experiences on marae have taught me to take each thought and allow it to wander back for 
a while into history, pause significantly in the present, and nurture it through into the future" (2015, p.42).

\section{Summary of Literature Review}

The literature has been reviewed in four sections in order to form a coherent picture of where this kaupapa sits. Firstly, Indigenous music therapy practices were discussed, with an emphasis on Māori music therapy research such as that by Kahui (2008) and Hodgson (2014). Previous success for involving both taonga puoro and other elements of te ao Māori within Music therapy were examined and compared (Hodgson, 2014)(Kahui, 2008)(Fletcher, Green, Macdonald and Hoskyns, 2014). These are compared to work from other cultures where authors acknowledge connections with ancestors and the natural environment as important elements within music therapy. Wider music therapy approaches are compared to approaches from within te ao Māori and to the work of nga taonga puoro itself. It is acknowledged that there is a significant lack of literature involving the use of Indigenous instruments and worldviews within music therapy, and this is cited as being an area where further research is needed (Kenny and Fraser, 2012).

The potential and power that nga taonga puoro hold therapeutically was explored. The ancient traditions of taonga puoro are acknowledged through the work of Richard Nunns (2001) and Hirini Melbourne (1991), with particular acknowledgment given to the use of the instruments in ceremonies and their intrinsic links with te taiao - the environment. The revitalization of taonga puoro is discussed and the use of the instruments is cited as being a form of decolonization and of tino rangatiratanga, as well as a tool to heal both individuals, the wider Māori community, and the environment (Nunns, 2001). It appears that being able to link puoro back with the environment is a crucial therapeutic component that honours and strengthens the core of a te ao Māori therapeutic practice.

The literature traces the whakapapa of current Māori mental health, investigating the effects of Māori land confiscation, mistreatment within the health system, lack of understanding around Māori health concepts within health services, and the second migration as some of the possible reasons for declining mental health. It is acknowledged that Māori 
engage more successfully with health services and clinicians who are culturally competent and engaged with te ao Māori (Cram, Smith \& Johnstone, 2003). Accessibility appears to be a withstanding issue for Māori within the health care system and often within their own culture, such as those affected by the second migration. Being able to assist Māori to access their own therapies and to improve practices of therapists to sit within te ao Māori could help to alleviate some of these issues.

It has been observed that reconnecting with culture has the potential for successful health outcomes for Māori, by reconnecting with te taiao, nourishing wairua, and increasing connection with te ao Māori. The healing potential of the instruments has been acknowledged as a powerful tool within our culture, and further research into this area could provide positive changes for Māori health outcomes, allowing us to use our own technology to heal ourselves. By supporting Māori to access their own treatments and live in ways that they individually see as being crucial to their culture, we are able to further nourish and support the mana of Māori as individuals, and of mana Māori as a whole. Across the literature I have noted three main thematic areas for Māori mental health, taonga puoro, and Indigenous music therapy practices. These are environment, accessibility, and mana. I will be taking these themes forward into my first cycle of research.

\section{Research Question}

I have utilized the reviewed literature to formulate a research question that aims to both honour the foundations laid by our tupuna of Māori health care and taonga puoro, and aims to see how I can utilize taonga puoro to help alleviate some of the results of issues outlined within the literature. My research questions is; How can I as a Māori music therapy student develop the use of taonga pūoro in my practice to support client recovery in an inpatient mental health setting? 


\section{Theoretical Standpoint}

This research utilized Kaupapa Māori Theory (see following sections), a theory developed through the education debates of the mid 1980s in order to assist with reclaiming research for us as Māori. Kaupapa Māori theory has been largely developed by Mana Wahine and educationalists such as Linda Tuhiwai Smith (2005), Leonie Pihama and Kuni Jenkins (2001). Other music therapy research into te ao Māori has also used this theory such as that by Hodgson (2014), and Kahui (2008). As wahine Māori, and as a researcher within the te ao Māori sphere I feel that it is my right to use this theory to work with fellow Māori to develop research that will benefit Māori, and that will enable us to show the power of taonga puoro in music therapy to both our own community and the wider world.

As it utilizes Kaupapa Māori Theory, the research also comes under a constructivist paradigm (Smith, 1997). Constructivism works well with action research also as the two share the view that we construct our knowledge of the world by experiencing phenomena, then reflecting on our experiences to establish what we understand to be true (Wadsworth, 1996). Kaupapa Māori Theory is also informed by critical theory, which is also one of the theories that underpin Action Research. Critical theory is a sociological theory that values the critique of culture and society by using knowledge from the humanities and social sciences to bring about societal change (Geuss, 1981).

\section{Kaupapa Māori Theory}

Kaupapa Māori Theory is a way of conducting research where Māori work with Māori to create research that will serve to benefit us as Māori, working in ways that fit within a Māori worldview and helping its users to engage in "culturally safe" research (Smith, 1990). One way that Indigenous research pathways can be advanced is through community action projects (Smith, 2005). Within this style of research the process itself is as important as the final result. According to Smith (1999, p. 128); "Processes are expected to be respectful, to enable people, to heal and to educate. They are expected to lead one small step further towards self-determination". Research conducted in this way becomes a fulfilling experience for all involved, as well as for all that may benefit from its application. 


\section{Principles of Kaupapa Māori Theory}

Kaupapa Māori Theory was originally based around a series of six principles as defined by Graham Hingangaroa Smith (Tino Rangatiratanga, Taonga Tuko Iho, Ako Māori, Kia piki ake I ngā raruraru o te kainga, Whānau and Kaupapa) in 1997. This was then expanded to eight principles by theorists such as Linda Tuhiwai Smith (2005), Leonie Pihama (2001) and Taina Pohatu (2004). It is to be noted that Kaupapa Māori theorists such as G.H. Smith (2005) and L.T. Smith (2005) state that the theory is part of a way of thinking and conducting research within Te Ao Māori, which makes it difficult to compartmentalize this thinking into meeting certain criteria, which is often how Pākeha research models are used.

I have included an outline of the following principles and how they relate back to my research from those outlined by Smith (1990) and have adopted the translations below;

\section{Tino Rangatiratanga - The Principle of Self Determination}

This refers to the need for Māori to have autonomy and self-determination within research about Māori. Within my research, clients were informed as we worked about the research I was developing through my process, and had their opinions and knowledge taken into account. Clients were encouraged to make their own choices in regard to the direction and activities within their therapy, which is part of a human centered approach.

\section{Taonga Tuko Iho - The Principle of Cultural Aspiration}

This principle acknowledges the centrality and validity of te reo Māori, matauranga Māori and tikanga. Within the therapy conducted using taonga puoro, the kaupapa was viewed through a te ao Māori lens in which clients were encouraged to think holistically about where taonga puoro sit within te ao Māori. The sessions were also based around matauranga Māori with a high value on te reo. Clients were taught the tikanga surrounding the instruments so that they were culturally safe.

\section{Ako Māori - The Principle of Culturally Preferred Pedagogy}

This refers to teaching and learning practices that both occur naturally within te ao Māori, and those which are preferred by Māori. Within the sessions, clients were 
offered a wide range of opportunities for learning about taonga puoro and its therapeutic relevance in a range of learning styles including kinesthetic, visual, reading/writing and auditory. Group sessions were based around a wananga style of facilitation where all group members knowledge was valued and contributed to the learning of the rōpū as a whole.

\section{Kia pike ake I ngā raruraru o te kainga - The Principle of Socio-economic Mediation}

This acknowledges the need for initiatives that assist to relieve the pressure or disadvantages that can affect Māori and their communities; encouraging researchers to create research that benefits Māori, and doesn't just use us as test subjects. Through my research I have created a model for working in taonga puoro music therapy, as well as having developed a programme using taonga puoro within mental health units allowing me to advocate for Māori being able to receive rongoa Māori based therapies within hospital settings.

\section{Whānau - The Principle of Extended Family Structure}

This critical aspect acknowledges the connection Māori have to their family, and to the whakapapa that connects us to our world. Within work at the facility, work with individual clients valued family, whakapapa, and saw the family as a system. Clients were invited to look to their whakapapa and attributes of it for strength in therapy, as well as engaging in mihimihi with myself in order to establish connections between us so that we could work together more fully in therapy.

\section{Te Tiriti o Waitangi - The Principle of the Treaty of Waitangi}

This principle was developed by Pihama (2001) and refers to the importance of te Tiriti o Waitangi within Kaupapa Māori research, affirming the tangata whenua at all levels from whānau, to iwi, to Māori as a collective. While developing my practice I consulted with experts in taonga puoro from iwi around Aotearoa to ensure that a variety of perspectives and knowledge was included within my practice. I also consulted with facility kaumatua, who were representative of our local iwi to make sure the tangata whenua were a critical part of development. 


\section{Āta - The Principle of Growing Meaningful Relationships}

This principle was developed by Pohatu (2004) to acknowledge the importance of building and nurturing relationships with Māori within research. It gives value to holding space for clients, and values reciprocal relationships. Holding space was an important part of my therapeutic work, as was building connections with clients through mihimihi and wananga. The development of a taonga puoro music therapy program and model came as a secondary result to providing clients with taonga puoro based music therapy that was tailored to each client's needs.

\section{Te Whare Tapa Wha}

The placement uses 'Te Whare Tapa Wha'; a Māori model of health created by Sir Mason Durie (2017). Where Kaupapa Māori Theory has its roots in education and the Māori renaissance that began in the mid 1980s, 'Te Whare Tapa Wha' is a health based theory that was developed during this stage in Māori academic development (Durie, 1985). Durie also explores interface research; examining the relationships and discourses between science and Indigenous knowledge, stating; "Indigenous knowledge cannot be verified by scientific criteria nor can science be adequately assessed according to the tenets of Indigenous knowledge" (2004, p.1138). He also acknowledges the ability of Māori researchers to apply the methods and values of both systems to their research, in order to create more comprehensive understandings of health.

I chose to use this model when working with clients within my practice, as well as using it to ensure my own needs as both a researcher and therapist were met so that I could ensure that clients were receiving the highest level of care I was able to offer. This model is based around a wharenui with four walls or supports; Taha Tinana - Physical Health, Taha Wairua - Spiritual Health, Taha Whānau - Family Health, and Taha Hinengaro - Physical Health. As the model is also based on the concept of a wharenui, it has deeper meaning where the wharenui and model itself is built upon the bones of tūpuna; acknowledging our deep connections with whakapapa and whenua. Clients were also educated about the model within 
their therapy, and were taught about how to use it as a resource for managing their own hauora both within the hospital, and as a resource they could use after discharge.

\section{Carolyn Kenny and the Field of Play}

My practice, and by extension my research, was also influenced by Carolyn Kenny's 'Field of Play' philosophy of music therapy (1989). Kenny was a Choctaw scholar whose theory supports an Indigenous worldview with values such as appreciating beauty, valuing nature and natural resources, creating ceremonies and rituals within therapy, and valuing relationships. Much of Kenny's worldview is in line with a Kaupapa Māori approach, that gives value to the relationships built in music and acknowledges the connectedness of all people and things. Kenny's work influenced my practice in many ways, including her view that all people who enter therapy are inherently whole and complete. Her holographic model pays acknowledgment to the complicated interweaving of elements within therapy that work together to create "The Field of Play" where clients are able to create music freely and openly in a way that allows the full person and their aesthetic to be expressed and changed, as well as to change that of the therapist themselves (Kenny, 2009).

Kaupapa Māori theory allows us to explore and unite with other Indigenous methodologies, helping to weave a global community of Indigenous researchers. Before her passing, Kenny worked with Indigenous scholars, Tina Ngaroimata Fraser, and Therese West to investigate and foster links between music therapy and Indigenous world views and practices. They suggest further research and development into this field (Kenny \& Fraser 2012; Kenny \& West, 2017). My research aimed to follow their recommendations and build upon their research by developing ways of using Indigenous instruments within music therapy, in a wholistic way that valued Indigenous ways of being and knowing including acknowledging connections with nature, therapeutic space, and ritual within therapy. 


\section{Methodology}

This is a qualitative study that uses an action research design, specifically practitioner-based action research. Qualitative data analysis works well with music therapy as it allows us a wide scope to incorporate a range of experiences, ways of communicating, and resources into our research to create a rich picture of what we do as therapists and researchers (Smeijsters, 1997).

\section{The Action Research Process}

Action research is an emergent process consisting of the repetition of a series of cycles of inquiry with stages such as planning, action, reflection and results (or input, transformation and output) which are then repeated, each time with new information and results, allowing the researchers to further their process and progress with each cycle (Costello, 2003). Lewin, one of the pioneers of action research, described this as 'the spiral of steps' (Lewin, 1946). Action research is largely defined by the way that its participants are also its" researchers, participating in a "community of practice" (Wenger, 1998). Each person's contribution to the research is rated equally on what they are able to contribute in a fair, and community-centered way. The results of action research are often embedded within the study itself, with changes being made in the practice of the action researcher, or within the communities or individuals that partake in the research as they themselves discover more information and new ways of doing things according to their needs, embedding the needs within the means.

\section{Theories of Action Research}

Action research is underpinned by a series of theories including feminist theory, critical theory of the Frankfurt school, and social theory. These theories amongst others have been developed in a variety of ways, including for example: Argryis' Action Science 
(Argyris, Putnam \& Smith, 1985) which focuses on changing variables after each cycle when new information has been discovered and applied, Heron and Reason's co-operative inquiry (Heron, 1996), who's major ethos is to collaborate with people on research rather than to do it on them or for them, Freire's Participatory Action Research (Freire, 1970), which encourages the participant to be active in the process rather than passive, and Barry's living education theory approach to action research, which challenges the academic in charge of the study to go beyond the status quo of their discipline and to seek further improvement for the sake of their participants (William, 2013).

\section{Practitioner Research}

Practitioner research is a form of self-reflective action research used to improve one's practice (Fox, Green, \& Martin, 2007). Practitioner research allows for professionals to study closely their own ways of doing, within the context of their work, and facilitates critical thinking and reflection on practice in order to develop both individual practice, and the professions as a whole. It is a well-used method in a range of humanities based research including social work, teaching, and music therapy (Fox, Green, \& Martin, 2007).

\section{Suitability}

Practitioner research allows the researcher to be an active participant in the research, and is an excellent way to engage with self-reflective professional development (Whitehead $\&$ McNiff, 2006). The values of action research are in line with the values of music therapy as music therapists and trainees are required to reflect and improve on their practice as they go. Action research is an established method within the field of music therapy research (Rickson et al., 2014; McFerran \& Hunt, 2008; Baker, 2007) which shows further evidence towards its relevance and application in the field. In this study, participatory action researched may have gathered more in depth results over practitioner-based action research; however due to the length of the project, and ethics concern around working with vulnerable people, this was deemed to be unfeasible. 
From an Indigenous perspective, action research also allows for the indirect participants' (who in this case are from a wide range of backgrounds but are working with kaupapa Māori) knowledge and experiences to influence the process and within that to influence my development as a music therapist. In my work, I have been moved by clients who have picked up the taonga and shown me their ancestral knowledge, and I have felt inspired to include what the clients themselves can teach as a part of my research. I feel that action research will allow for a non-hierarchical approach which is both in line with music therapy principles, and with a kaupapa Māori approach. This research method also works well with both CoMT and HMT, as both priorotise and acknowledge the inherent mana of clients and their right to Tino Rangatiratanga.

\section{Method}

I completed three cycles of action research. Each period of onsite action/data gathering was two weeks in length preceded by planning, and followed by a three-week period of analyzing, and planning ideas for the next cycle of research. Data was collected in the form of my usual clinical notes, documenting interaction with participants at the unit, and staff, my reflective practice journal which includes artistic responses as well as writing, and conversations with staff. Data were collected from sessions relevant to the research within the facility, with specific emphasis on a taonga puoro music therapy session that I was running weekly at the facility. Though I would have liked to use other sources such as video and audio recordings it would not have been pheasable due to the vulnerability of the clients involved.

At the conclusion of the three cycles, findings were collated, synthesised and written into my final exegesis with support from my supervisor. During this time, I attended placement for approximately three days per week. 


\section{Analysis Method}

During the data collection cycles, data was gathered in the form of reflective notes from all sessions involving taonga puoro or work relating to taonga puoro. Each intervention was entered into the coding software NVivo (QSR International, 2014), with a separate source for each session or related event. The method of data analysis and instruction for use of Nvivo came from Bazeley and Richards (2000).

Action plans were then used as top codes in order to sort data into focus areas, this was used in order to effectively sort what was often a large amount of data into more manageable areas. After the data had been sorted into top codes, open coding was used under each top code to find meaning groups underneath each action cycle. Some examples of the coding of data are presented in Appendix III.

Meaning groups were then compared both within top nodes, and across the entire data cycle, in order to examine correlations and patterns within the data. These results were then synthesized into a report for each cycle to explain, sort, and connect the findings; which is what appears within this exegesis.

\section{Ethical Considerations}

This project has been approved by the Victoria University of Wellington's Human Ethics Committee under the New Zealand School of Music (NZSM) Music Therapy Programme for NZSM 526 student research, Ethics Approval number 22131. Providing that the research is of a self-reflective nature, either action research or secondary analysis of data.

Although my project comes under action research for the purpose of the development of my practice, my clients were involved as indirect participants. I consulted with the team leader at my placement as well as my clinical liaison and received consent from the facility (see Appendix I).

All efforts have been taken to anonymize sensitive information and the District Health Board Code of Conduct, Music Therapy New Zealand Code of Ethics, and Victoria 
University of Wellington's Human Ethics Policy was adhered to throughout the research process. The name of the facility itself has not been used within this exegesis in order to protect clients' identification. There is still a small risk of client identification from the research which has been discussed with the facility.

For the vignettes contained in this thesis from therapy done with particular clients to demonstrate certain parts of the action research process and findings, clients have been consulted with and informed consent attained. For clients who were unable to give consent, informed assent was attained as well as consent from second or third parties where appropriate (see Appendix 1).

As my research is based around kaupapa Māori, I have consulted with the kaumātua of my facility, a Māori co-supervisor of my research, have sought bi-cultural supervision for my clinical practice, and consulted with many experts in the field of taonga puoro to make sure that tikanga and the cultural needs and safety of my clients has been met. I see this as an ongoing process that is crucial in te ao Māori to ensure the passing of ancestral knowledge continues and to pay tribute to our tūpuna and our way of acting within te ao Māori.

\section{Māori and Tauiwi}

As this is Kaupapa Māori research, it has been done by Māori, for Māori. Though it is to be noted that this research was done in a ward including people from multiple ethnicities. For the sake of space, I have decided not to dwell too heavily on the impacts that this study has for Tauiwi, though have included points where Tauiwi responded specifically to interventions, and how this was done inclusively as part of my normal music therapy practice. The vignettes included are mostly from clients who identify as Māori, but there are also vignettes from the perspective of Tauiwi to ensure a balanced sample and show how this kaupapa worked for clients from both groups. 


\section{Working Towards a Model}

As is a part of kaupapa Māori theory, this research aimed to create a usable model as part of its findings. In order for this model to be as adaptable to needs of each individual client it may be used by, the research focused on discovering overarching values and techniques for working with taonga puoro within music therapy, rather than focusing on researching how to play the instruments themselves. I found it was beyond the scope and limits of the current study to do this, though clearly an important topic. If readers are interested in the specifics of learning any of the instruments referred to throughout this text, I recommend the book 'Taonga Puoro' by Flintoff, Melbourne and Nunns (2004). As well as engaging with players of taonga puoro in person. 


\section{Findings}

\section{Cycle One: Planning}

Actions for this cycle were decided by reviewing the literature, as well as from observing themes within preliminary data from clinical notes at some initial Haumanu Rōpū (taonga puoro music therapy group) sessions held within the facility. This raised three major topics that were resonated through my thematic analysis; mana, environment, and accessibility. I then worked to find a focus area for cycle one from each of these three themes. Under mana, using storytelling within therapy, under environment, increasing the visibility of taonga throughout the unit, and under accessibility, crafting instruments with clients.

\section{Cycle One: Actions}

I felt that by creating a culture of storytelling, and giving value to the stories shared by clients, I would be able to pay tribute to, and honour their mana. Using storytelling within therapy was facilitated by incorporating Māori legends into sessions and having group members work to create soundscapes and soundtracks for these narratives. Storytelling was also encouraged within the group context where clients engaged in mihimihi and would contribute stories to the wananga style sessions that the group engaged in. An example of this occurred, when a young man who was on the periphery of the group overheard us telling the story of Hinemoa and Tutanekai, using our kōauau. He came over and told us that he had been to Mokoia island on a waka as a boy. The group, and the staff listening in, were surprised to hear this as the young man was usually so quiet. Seeing him be the center of positive attention was a beautiful thing to witness; his mana shining through. Within individual therapy, clients would also share stories about whakapapa and would be encouraged to think about how they could relate their own stories back to those of the instruments. The stories of the instruments themselves, both as individual taonga, and as categories were also shared with the group. 
Increasing the visibility of taonga throughout the unit was facilitated by involving taonga puoro within multiple aspects of the activities and proceedings at the unit. Taonga were shown at the clients' morning meetings, which made the meetings an activity that promoted whakawhanaungatanga and payed tribute to the traditional uses of the instruments, such as the Pūtātara. The instruments were also made available and visible within all therapeutic sessions I conducted at the facility. I also worked with staff in the occupational therapy department to incorporate taonga into other activities such as wellness groups and facility trips. Some staff at the facility who showed an interest in taonga puoro were further educated about the use and playing of the instruments, and some were supplied with instruments that they could use on the ward.

Crafting instruments with clients was facilitated by the introduction of a group where clients were able to create their own kōauau, karanga manu, and porotiti on the ward by using a low risk method I developed using air dry clay and blunt tools. Woodwork groups in which clients crafted taonga puoro of their own design were also used by patients with lower security risk. The woodwork facility that we partnered with for this element of the project also provided us with some blank kōauau that clients within the ward were able to finish and customize.

\section{Cycle One: Findings}

I had three main actions for cycle one which served as top codes. These were 'Stories and Legends', 'Visibility and Accessibility' and 'Client Creation'. Each main action had a series of codes to closer examine different aspects of the action and to investigate connections between codes, allowing me to figure out what worked well and what needed more work.

Under 'Stories and Legends', the codes were 'Stories with links in reality', 'Stories encouraging the sharing of positive stories', 'Stories as opportunities for cultural sharing' and 'Stories extending interest or music making'. I feel that some of the most outstanding therapeutic moments from this cycle come from 'Stories with links in reality'; in which 
clients were able to find personal or real life connections with the stories around the instruments and feel that they were part of a wider world outside of the group and the unit. There were strong correlations between 'Stories with links in reality' and two of the other sub nodes; 'Stories encouraging the sharing of positive stories' and 'Stories as opportunities for cultural sharing'. The use of stories that clients were able to see as reality based, such as that of Hinemoa and Tutanekai, often encouraged clients to share their own stories that related back to the kaupapa. These stories were mostly of a positive nature and could be used to reframe positive memories as important, and would be used to inspire other activities within therapy. Regardless of whether clients perceived stories as reality based or not, stories assisted with the sustaining of music making which comes under the code 'Stories extending interest or music making'. The desire to follow a narrative appeared to assist people with sustaining music making, attendance and interest, in order to find out how stories ended and how this related back to what the group was doing. Through this code it was reinforced to me that stories and legends are critical within te ao Māori. I have often heard it said that Māori are traditionally orators, and I hadn't valued my own skills in this area properly, or what this skill could offer therapeutically until this cycle.

Under 'Visibility and Accessibility', the codes were 'Taonga as coping mechanism', 'Normalisation of taonga', ' Taonga as a way in to music therapy / way to support music therapy', 'Taonga viewed as taonga', and 'Levelling opportunities'. The most referenced data throughout the analysis was the code 'Normalisation of Taonga'. I feel that because of my efforts to normalize the use of taonga in therapy at the facility, clients have mostly seen this as a normal part of what I do as a music therapist, and for some of them this is the only way they have known music therapy, which further normalizes this to those clients. When clients saw others interacting with taonga like it was a normal part of therapy, they often seemed more able to engage with it themselves. However, this did cause some issues around the concept of people viewing 'Taonga as taonga' and not just as another instrument. When people were able to see objects as precious, the idea of being trusted with them or being taught to play them seemed more significant therapeutically, as compared to when people were unable to understand this connection. For some people taonga provided a link into wider music therapy, as in a group context it was often something that was new to everyone unlike traditional instruments. The contrast in appearance and sounds of the instruments as compared to western instruments also made them stand out and this often drew people in. 
Perhaps, not knowing how the instruments sounded or were meant to be played helped people to experiment without a fear of being 'wrong'. This related to the accessibility of 'Levelling opportunities', as within the taonga, there were a range of levels of instruments to be played. This meant that there was at least one instrument that could be played by each person, creating a place for everyone within the music, however when people viewed the percussive instruments simply as sticks or rocks and not as taonga, this caused new problems. Linking the more simple instruments with stories of their whakapapa helped participants to be able to feel confident in tasks that were suitable to their level. Something that really stood out to me in this category was 'Taonga as coping mechanism'. The portability of taonga worked well for clients to be able to use it outside of the therapy room as a coping mechanism. Utilising taonga as a coping mechanism was selected both by staff such as the use of tumutumu rakau as a coping tool for outbursts in a man with Obsessive Compulsive Disorder (OCD) and Aspergers to match heightened emotion and then decrease these behaviours, and by patients themselves such as a woman wanting to learn the kōauau so she could play it whenever she wanted to smoke. I feel that this work could be developed further as it was particularly effective with these clients.

Under 'Client Creation', the codes were 'Opportunity for individual or individual focused work' and 'Opportunity for value of skills outside of playing within the music therapy process'. I had thought that client's creating their own instruments would help to facilitate playing outside of groups. However, once clients had made instruments, even if they were made to be worn and they had learnt how to use them, they still did not appear to use them outside of therapy. However, working on instrument making had some surprising benefits. The code 'Opportunity for individual or individual focused work' showed that people who wouldn't usually attend music therapy were given opportunities to engage in a way that was comfortable to them. Within this individual focused work, I was given opportunities to value skills outside of playing and how they could be worked into the music therapy process. 


\section{Vignette One}

Opportunity for Value of skills outside of playing within the music therapy process. Example one: Jan

9/05/18

Jan had been on the ward for around six weeks when she came to my group to craft instruments. She had shown limited interest in both music therapy and occupational therapy groups before this point, showing low motivation and a limited ability to sustain participation. She had sat on the outskirts of haumanu rōpū before, but had found difficulty staying for any length of time. When she came to the table, I showed her the instruments and how they sounded when completed. I showed her how the designs were basic but that she could elaborate or personalise them however she wished. We talked about the whakapapa of the karanga manu, and talked about a shared love of bird song. Then, Jan began to craft her karanga manu, she focused and I played some of the instruments with some other clients while she worked, pausing to check in with her and using the music to support her focus. At the end, she proudly showed me a karanga manu that she had made in the shape of a bird itself. She beamed at me and I praised her for her ingenuity and creativity. After her piece dried, I offered to teach her to play it. Sadly, she declined, but she asked to hear it played within our music therapy session. I played bird calls on her karanga manu while she played piano with me. She asked if she could have the karanga manu stay with the ward as a thank you for what they had done for her, to which I agreed after checking that she was sure several times over the rest of her admission as her mental state improved. From then on, Jan was more engaged in the activities programme on the ward. Through this interaction, staff found that she had in fact been an artist prior to her admission. I feel that having the support from this group helped her to re-engage with an activity that was meaningful to her.

Under 'Opportunity for value of skills outside of playing within the music therapy process' I found people wanting to use their skills to help the rōpū. I was also able to appreciate people's desire to create in a traditional way, following the tikanga of giving away first instruments and learning the whakapapa of the instruments they were creating. I feel that investigating ways to join creating instruments and playing them within therapy would be a 
good avenue for future research as the creation alone did not help to facilitate this in the majority of situations.

Within the analysis process, I also found a significant amount of data under 'Personal Mana- Feeling Challenged' which largely came from sessions with my supervisors, as well as from my own personal reflections. I coded this as I thought this could be an important avenue for an action plan in a future cycle. I found that feelings of incompetency, both cultural and musical, often affected my ability to work and to feel like I could hold people safely within the fields of both taonga puoro and music therapy. I feel that as this work is so personal to me, both as a music therapist and as Māori, I need to feel as secure as I can with what I'm doing, in order to pass that feeling on to my clients and to feel safe myself. Through supervision I saw this as being not only important for myself and my clients, but an important part of the learning process as a whole and an area that deserved further investigation and acceptance within my work.

\section{Cycle One: Conclusions and Preliminary Plans for Cycle Two}

After analyzing the data, I found two main areas that stood out for development in cycle two. I felt that working to create real world connection for taonga puoro within music therapy was an important direction to take as it acknowledges the value for clients of being able to connect therapy to the world outside the hospital, as well as helping to create the basis of a sustainable practice were clients are able to continue with their music after leaving therapy.

The other avenue I chose was to focus on my own mana and ability to hold space for people both culturally and musically. This direction acknowledges the importance of selfsustainability as a therapist, and the importance of seeking supports from te ao Māori for myself as a Māori clinician. 


\section{Cycle Two: Planning}

The actions for this cycle were taken from the results from cycle one. I decided to focus on just two avenues for this cycle, as a means to acknowledge and focus on my personal stability, and to focus more in depth on the topics chosen. The topics for actions in were, Personal Mana and Real World Connections.

\section{Cycle Two: Actions}

For Personal Mana, I decided to seek support from bi-cultural supervision in order to fill the gaps within the supervision I was using, and to deepen my knowledge and relationship with my own whakapapa. In order to do this, I had to acknowledge many of the insecurities that I had myself around inhabiting a Māori identity, which was challenging for me as a fair skinned Māori, as many Kai Tahu are. But the benefits and confidence I received from engaging in this personal work served to benefit my clients as well as myself, which gave me strength to do it. I also focused on creating safe spaces in which to conduct work, as I felt that having a more therapeutic space would help both clients and myself feel safer and more comfortable in therapy. I also aimed to use taonga puoro to assist with my own well-being, taking time to play for myself, not just for others.

For Real World Connections I aimed to connect taonga puoro within the ward, with communities, activities, and events outside the ward. This was done by acknowledging elements of the wider te ao Māori such as the maramataka and events such as Matariki.. Clients learnt waiata about Matariki, and together we engaged in a facility ritual within haumanu rōpū where they were encouraged to let go of things from the previous year, and embrace a new start. We used taonga puoro throughout this ceremony, doing improvisations on how our last year had been, and on our hopes for the new year ahead. Through this topic I also aimed to build connections, which I did with the help of a local museum and woodwork workshop in order to help clients form connections that they could then use upon leaving the unit. 


\section{Cycle Two: Findings}

For this cycle I had main topics, labelled Personal Mana and Real World

Connections. Both the top nodes had a series of codes which helped to examine closer the data, to better find correlations between codes, and to then form ideas for the next cycle of action.

Under 'Personal Mana' were three codes; 'Acknowledging feelings of insecurity or frustration', 'seeking support from culture and community' and 'Creating or being in a safe space'. Surprisingly, 'Creating or being in a safe space' was referenced the highest out of these codes, with thirteen references from six sources. Through this I found that being in a space that met my needs as a therapist and a Māori clinician, helped me to feel comfortable within myself and to achieve my full potential as a therapist. The more inviting and engaging the space, the more the clients were able to work, as they were experiencing the space themselves as well as sensing my increased comfort and ability to meet their needs. This brought me back to Carolyn Kenny (1989), and her ideas around "the musical space". It seemed in my context, that this wasn't a permanent physical space that would always work, but rather a space that met the needs of the people I was with and the mental space they were in at the time of therapy. 


\section{Vignette Two}

Creating a Safe Space: 1

Example One: Marcus

$11 / 06 / 18$

I was working with a client with a weapons risk in the medium security ward.

Because of the situation, I chose to work with him in the open area rather than in the closed off music room. We were in a wide-open space with lots of natural light, and after playing several songs in this space, the client started to change his body language from defensive, to receptive. I asked what he'd like me to play and the client was curious about my kete of taonga, "try that one" he said and pointed at a bone kōauau. I began to play it on top of his chords, using the kōauau to bridge the abruptness of his chord changes and add ostinato above what could often be a disjointed set of chords. As we played, more and more people from around the ward came into our space. I took out my kete and gave them rakau and hue puruwai after the client acknowledged that they could join us. Our new group sat together in the following the client's music. We laughed together, learnt about the instruments, and celebrated music in a space that seemed to support each of our needs equally.

\section{Vignette Three}

Creating a Safe Space: 2

Example Two: Sarah

$15 / 05 / 18-18 / 05 / 18$

A client with depression and self-harm issues attended haumanu rōpū on the low security ward, the space had large glass panels looking out into trees, birds, hills and sky. We sat on couches with the instruments in front of us. All the clients in this setting knew each other well and were happy to interact with something new together. This session also included listening to pre-recorded taonga puoro music while drawing a response to the music, then sharing the meanings of our drawings. 
The client assisted with playing some live music for people to draw. We all spread across the floor, as she played pūtōrino and nguru, with me on tumutumu, kōauau and porotiti. Afterwards the clients described their drawings to her and commented on her beautiful playing. After the session ended, I recommended following up with her on another day. She agreed, saying she "really enjoyed" the instruments.

When I next saw her, it was the day after a point of crisis. I came to her room and asked if she'd still want to work... she was disorientated and her room had a feeling that I can only describe as negative wairua, but she agreed enthusiastically. We chose to work in the sensory room; a small space away from other clients, with comfortable chairs, lights, and a view of trees and hills. When we arrived, I laid out a range of kōauau on a special cloth on the floor as well as the instruments we had used within the group. I said karakia over the instruments, and then together we began exploring. I told her about how these kōauau had been donated to the ward and its clients, and that I think it would be really beneficial for her to have one. She agreed, and we decided to play through them until we found the right one. We stayed there around the mat for around an hour, as she would pick up and play different kōauau, with me supporting on kōauau, vocals, porotiti and tumutumu. After we played each one we would wait and enjoy the quiet of the space, watching wax eyes flit in and out of the tree by our window. She would often break the silence with a story or comment, and I would talk with her about her experiences, and about similar stories from the whakapapa of the instruments.

Soon, she picked up a long totara kōauau with three wenewene. As soon as she played it she said "this is the one". She commented on its shape, feel and sound. She began to play and I joined her on the kōauau I feel fits me best, information I had shared with her at the beginning while we were discussing how she would choose. We wound the session to a close and she talked of future plans of going "into nature" to play and take time for herself. When she had first entered the session, Sarah had visible tremors in her hands. I noticed as I said goodbye to that these had subsided during our mahi. I was later told by a support worker, that she had taken the client out into the bush later in the week where she had chosen to play her kōauau. I felt proud knowing that she had been able to find her own therapeutic space and keep engaging with taonga. 
Creating a safe space in this work is very individual, I perceive it as a combination of the physical space, the people present, the materials being appropriate for the clientele, and the therapist being open and comfortable within the space. I noticed the more open I was about my journey and who I was, the more others were able to find connections and engage.

The second most frequent code, which was related to therapeutic space in many ways, was 'Seeking support from culture and community' with eleven references from thirteen sources. I decided that I needed to make contact with a cultural supervisor as I had been experiencing a lot of issues that I felt were not able to be dealt with within my usual supervision.

\section{Vignette Four}

Seeking support from culture and community

Example One: Koukou and Tieke

$17 / 06 / 2018$

When I went to cultural supervision, I was surprised at the issues that came up for me. I acknowledged that often I feel guilty about what I don't know, and I feel as if there is no whakapapa behind me to warrant who I am and want I'm doing. I also acknowledged feeling that I am too young to embark on what is an important kaupapa. Within cultural supervision, I was encouraged to think of the tūpuna I have, and what their skills were that I may have within me. I thought of Tieke / James Loper and Koukou. James Loper left the United States in his early teens, travelling to Aotearoa to start a new life as a whaler. In Aotearoa, he married Koukou, as the first Pākeha to marry in to my Ngāi Tahu whānau. After marrying into Ngāi Tahu he is given a new name, 'Tieke', named after one of our birds. As is Koukou, whose name means refers to the ruru and the sound it makes. I think of how brave they would have had to have been; Tieke to travel all this way and marry into a new culture and I think of Koukou bringing him into her culture and advocating for him to be accepted by the hapū, breaking the mould for love and what she knew was right. 
I have dreamt of Tieke birds in the bush. The dream starts with just one, and then soon the whole bush is alive with their movements. This dream comes back to me from time to time, always just as vivid. Another time when I was a child, a ruru came up to my father, and when he reached out to it, flew onto his arm. I remember him opening up his jacket and showing me, as it sat calmly in his jacket looking at us. The ruru lived near our house and would often fly with us as we drove up the driveway, just ahead of the car. This again makes me think of Carolyn Kenny (1989), and the value she places on signs and dreams within our roles as therapists and musical healers, as we do within in Te Ao Māori. I see these occurrences as signs of support and connection with these tūpuna, helping me to see their attributes within myself, and giving me strength to continue to be brave, and innovative when I am feeling challenged. I think of this as reciprocal also, and often I work in the bush with nga taonga puoro, playing with ruru and tieke to give back to what gives me strength.

Through my supervisor's guidance, I began to see that being strong, brave, and innovative is a part of my whakapapa; a part of my DNA. I was able to reflect on how Tieke met Koukou in their youth, and how all important journeys must start from a seed, and that starting now gives me more time to develop and grow something I am passionate about. Like Koukou and Tieke, I feel that I am starting my life's work.

When I went back to placement after this support, I felt stronger within what I was doing, which changed how I behaved in therapy. When I didn't know something a client asked, instead of feeling unsure of myself, I was able to say that I didn't know it " $y e t$ " which felt like it was an opportunity for me to learn more rather than just another way for me to feel inferior or unworthy.

Through this time, I also looked closer into my own life, choosing to spend time reconnecting and strengthening my relationships with my family and with myself as a player of taonga pūoro, not just as a therapist. I felt that the act of looking back, and acknowledging that I have generations of strong people behind me, helped me to access the reserves of strength that I needed to access to perform therapy as best as possible. I also dedicated time to playing for myself, which I found helped to clear my mental state, as I often have the tendency to let clients stay with me long after the work day has finished. Ironically, I needed to take the advice I give a lot of clients and 
use the instruments for emotional release, clearing the mind, and connection with nature.

Doing these things helped me to look at family relationships within the ward in new ways, leading me to facilitate playing with a mother and daughter who was staying on the ward. Acknowledging how great these supports can be for myself helped to reaffirm how important they could be for others.

The last code under 'Personal Mana' was 'Acknowledging Feelings of Insecurity or Frustration' with nine references from eight sources. Through closely examining myself as a therapist and as a person, I found a tendency not to acknowledge feelings of fear, anger or frustration. I began to realize that not acknowledging these negative emotions could be a disadvantage to my work, and to my personal life as well. By using my reflective journal to note down my feelings towards these things and talking about it with supervisors or other health workers, I able to move through these feelings rather than suppressing them.

\section{Vignette Five}

Acknowledging feelings of insecurity or frustration

Example One: Health and Safety

\section{$13 / 06 / 2018$}

One experience I had with health and safety involved a hygiene concern being raised about the wind instruments being played by multiple people. When explaining the therapeutic value of the instruments to a responsible authority at my placement, using the correct names of the taonga, I was shut down. I understood that they needed to get their job done, but I felt like what I was doing was under-appreciated. This was something I took to supervision but was also something that I talked through with taonga puoro mentors of mine. Through this process, and through the process of undertaking bi-cultural supervision, I realized that the challenges that I face within my practice require support from a variety of areas including music therapy supervision, bi-cultural supervision, and the need for me to maintain my own wairua and relationship with my tūpuna and culture. Through this process I realized that changes 
within systems take time but accepting that and working towards that change is worth the effort.

Overall for 'Personal Mana' I realized the important of creating a safe and nurturing therapeutic space for both clients and therapist, the importance of seeking support from my culture and community, and the importance of being able to acknowledge difficulties I face as a clinician working with a te ao Māori framework.

Under the topic of 'Real World Connections', were the codes 'Connecting taonga puoro with communities outside of the unit', 'Taonga puoro as a living art form' and 'Seeing taonga puoro as a part of holistic Māori kaupapa'.

The most referenced code within the data was 'Seeing taonga puoro as a part of holistic Māori kaupapa' with nineteen references from thirteen sources. It is important to note that this data was collected during the Māori new year celebration 'Matariki'. So the entire occupational therapy team and I had made extra efforts to include kaupapa Māori elements within the unit. This affected the data as there was more support and opportunities for clients to engage with te ao Māori than usual. I found that when clients saw taonga puoro as part of a holistic Māori worldview and way of being they engaged better with the taonga puoro, and were able to see where it sat within te ao Māori. By using other elements such as karakia, whakatauki, waiata, and storytelling, clients received a broader understanding of the significance of both te ao Māori.

I anticipated that Matariki would also assist with 'Connecting taonga puoro with communities outside the hospital', but the two were not strongly correlated. My findings demonstrated how my efforts to form community links for patients using taonga puoro, including inquiring about forming a houmanu group outside of the hospital with help from a local museum (meeting occurred on 18/05/2018), and working with a wood work facility to help patients to build their own instruments (facility visited on 14/05/2018, as well as a follow up meeting on 18/05/2018). At the end of data collection I was still waiting to hear about the houmanu group, however the woodwork group has produced several kōauau that clients will be able to help finish as well as making prototypes with a hope that some clients will be able to craft some themselves. (During this stage of data collection), I did not have many people interested in creating their own instruments at the wood work facility, and the 
houmanu group was not established enough to be provided as a viable option for community engagement. I also made efforts to try get clients to Matariki events that involved taonga pūoro within the community, but the events were often in the evenings and staff were unable to help facilitate this. I found this disheartening, but it helped me to realize that as a single clinician, it wouldn't be possible for me to facilitate everything that I felt would help clients. Even with communicating and having a strong support network within the facility, the limits that people put on themselves are there for the purpose of protecting clinicians to avoid burn out, so that they can continue to provide high quality services for clients.

'Taonga puoro as a living art form' was coded with fourteen references with eight sources. Within this category, I found patients hadn't been supported to see taonga puoro as a living art form with an active community. When clients realised that taonga puoro existed both historically, and could be modified and developed in a modern context, they were able to experiment with taonga puoro and see ways that they could be a part of the art form. One way this was done was through listening to and appreciating modern taonga puoro artists such as Jerome Kavanagh, Alistair Fraser, and Richard Nunns. One client joined me in watching and appreciating these artists, and then showed interest in using a loop pedal as part of our session with taonga puoro as Alistair and Jerome had done. This helped him to learn a new skill, and see that though these instruments are sacred in many ways, they are also able to be modernised in our approaches to them. Showing clients modern taonga puoro players and sharing with them events and places that taonga puoro are used in within our communities also helped to provide them with resources that they could use without a therapist present, such as when they leave the hospital. Recorded music was beneficial for several clients who would listen to taonga puoro based music outside of therapy.

\section{Cycle Two: Conclusions and Preliminary Plans for Cycle Three}

Two areas I found that I wanted to expand on for my next cycle were; the therapeutic space, and the therapeutic relationship and being open as a therapist. I felt that focusing on the therapeutic space would assist in making clients feel more comfortable within therapy, and therefore allow them to engage with it more deeply, as was observed within 'Creating or being in a safe space'. This area too was inspired by CoMT which acknowledges the therapeutic environment and how a supportive environment created with an approach of 
universal positive regard and resourcing can help clients to achieve their full potential (Aaro \& Stige, 2011).

I felt that focusing on the therapeutic relationship and being open as a therapist was also an important area to research further, as focusing on my own strengths in therapy helped to bring out the strengths of others. Sharing elements from my own whakapapa and world view, could serve to deepen the therapeutic experience by encouraging clients to share and investigate theirs.

\section{Cycle Three: Planning}

The topics for my final cycle were 'Focusing on the Therapeutic Space' and 'Focusing on the therapeutic relationship and being open as a therapist', chosen through the analyses of findings from cycle two. The therapeutic relationship, and being open as a therapist, was a particularly important area of focus. This area was controversial in many ways, as maintaining boundaries are also a crucial part of effective and safe practice. However I felt that by sharing safe information that encouraged others to deepen their own thinking about their identity and worldview, was valuable and safe within our context, and is crucial to concepts such as whanaungatanga within te ao Māori.

\section{Cycle Three: Actions}

For 'Focusing on the Therapeutic Space' I aimed to use spaces around the ward more effectively, allowing clients more choice in what spaces we worked in, and utilizing under used spaces such as the sensory room and women's lounge as therapy spaces. Conducting therapy within view of nature was also an important aspect of this cycle, and preferences were given to spaces that acknowledged the natural environment when working with clients with a topic that was inherently connected to te taiao. I also adapted spaces to make them more inviting for therapy, such as moving furniture to better suit lighting, or bringing in natural elements such as flowers that were brought in for a session on Honginui 
(early spring) that could stay in the room to remind clients of the value of the session, and continue to change the environment after the session had finished.

In terms of 'Focusing on the therapeutic relationship and being open as a therapist' my actions were focused around sharing beliefs and personal experiences with clients in order to form deeper connections. In earlier cycles, when I shared my experiences with the instruments, or with my relationship with wider te ao Māori, clients would respond with their experiences and world views. One example of this occurred with a kōauau that I found at the edge of the south coast. I walked the beach, then took out a kōauau to mihi to Tangaroa. After playing for some time, I felt something gently nudge my foot, I looked down and saw what appeared to be a kōauau floating in the water. I picked it up and it played a sweet and piercing sound. I began to introduce this instrument this way in therapy, sharing my beliefs through doing so. Many clients would try guess what it was made of or how it ended up in the ocean, but just as many would acknowledge that they felt lucky to play an instrument that was a gift from Tangaroa. Through this topic, I also aimed to introduce concepts like wairua, mauri, and hauora which are central to a Māori worldview. Acknowledging moments where I was challenged, and my own limitations and gaps in my knowledge was also a focus to ensure sincerity within the therapeutic relationship. As previously mentioned, for this topic it was also crucial to think about personal safety, and what information to share, which was also a large focus for my personal reflections and weighed on my mind when planning therapy sessions. During this time I used supervision, and conversations with the head of occupational therapy at my ward to ensure my own safety, and that of my clients.

\section{Cycle Three: Findings}

For this final cycle I had two topics; 'Focusing on the Therapeutic Space' and 'Focusing on the therapeutic relationship and being open as a therapist'. The topics each had a series of codes which allowed me to closer examine the data and connections between nodes. 
There were a total of five codes underneath the topic of 'Focusing on the

Therapeutic Space'. These were 'Clients keeping a physical element of the space after therapy', 'Clients setting own rituals', 'Me or clients modifying or selecting a space to work in', 'Spaces within spaces' and 'Using music to transform the space'. The highest referenced code with twelve references across nine sources was 'Using music to transform the space'. I attribute this in part to the fact that at the facility, many people wish that they were elsewhere. As many people are held there under the care of the facility, the desire for being able to be outside the facility is often high, and because of the risk to themselves and the risk of leaving the facility without permission, many people are not able to leave the facility for some time when they are first admitted. Within the facility there is a lack of natural environments bar some sparse gardens. Often in therapy, people would want taonga puoro that were able to mimic the sounds of natural environments that they were away from. Hearing these sounds within music had a calming effect on the spaces. Clients would often all stop and listen to the instrument, many choosing to close their eyes and focus on the sound or commenting on how it made them feel like they were "somewhere else" (8/08/2018).

\section{Vignette Six}

Using Music to Transform the Space

Example One: Keriata

$10 / 08 / 2018$ - 27/08/2018

Keriata had been in the facility for several months, often she didn't interact with groups. One haumanu rōpū she was encouraged by other staff to come and "have a go". When she came over to the table, she found the poi awhiowhio. I asked her if she'd like to know how it sounded and she agreed. I spun it for her and she looked me straight in the eyes and said "bird". "Ae, kereru” I replied. I helped Keriata to learn to swing it, something she was tentative about at first, but soon she was using the poi awhiowhio with full confidence. Her eyes following the hue spin around and around. As she played, people on the peripheries of the group began to listen. Slowly, people moved forward and sat around the table. Everyone was silent listening to Keriata. When she stopped after several minutes, everyone continued to sit in silence. "Talking feels a bit like breaking the spell eh?" and everyone agreed. I thanked Keriata for her 
beautiful start to the group and explained to the group how the taonga belonged to Hine $\mathrm{Pu}$ Te Hue, the atua of peace. The group made comments on how it had made them feel peaceful to hear Keriata play.

In the weeks that followed, at the start of each Haumanu Rōpū, Keriata would come to see me before the group began to play the poi awhiowhio. At a point where she was particularly unwell, Keriata made a beeline for the table of taonga and pointed at her poi awhiowhio; "I remember that one". I invited her to play it and again, the sound of her music brought people into the space and calmed them. Again, people guessed the sound and listened intently to figure it out. "the bush", "a bird", "water", "a wood pigeon!'. When everyone heard the last guess they nodded and sighed. Keriata continued to play, as people closed their eyes and listened to the sounds of the bush far away.

I wasn't surprised to see the instruments invoking feelings of the atua they represent. This part of the research felt very affirming to me as Māori, knowing that our technology and healing methods work in their purest form. It showed me the value of being able to use music to transport people to another space where the want to be.

This vignette also represents; 'Clients setting own rituals' in which there were five references from five sources. Carolyn Kenny talked extensively in The Field of Play about the importance of ritual within music therapy. As my practice as a music therapist is heavily influenced by te ao Māori, ritual tends to emerge as a result of following tikanga and kawa. However, within this I realised I needed to let individuals and groups set rituals for themselves as well. For Keriata, this was starting the group with poi awhiowhio to bring everyone in and help them to calm down. It was important for me to be able to encourage moments were clients were coming up with ideas to create rituals and routines for themselves, and where possible I would support these ideas, as was in line with a HMT approach that encouraged exploration of self and identity both within the context of the individual, and in the context of the group. Some clients would need encouragement to feel what these rituals would be, but talking about trusting innate knowledge and asking them "How would you like this to be done?" often helped to facilitate beautiful moments in therapy. 
A lot of these rituals were based around client resourcing, where clients were able to select an instrument to keep from a gifted collection, or select another resource of personal significance that could be used outside of the therapeutic space such as whakataukī. These instances were coded under the code 'Clients keeping a physical element of the space after therapy". This issuing of resources according to interest and need was inspired by a CoMT approach, and was a part of the ethical standards of kaupapa Māori theory, to ensure that clients were able to continue with therapy that had been significant to them even upon discharge.This led me to think about what makes a space, and how can I use that to resource clients to continue therapy after the session ends? I found that when clients used resources from the space and where then supplied with some of the things they had used within this supported space, they were then able to take these objects and continue working after the session had ended. This included both written resources and instruments. In one session, I laid out a range of whakataukī on the table and encouraged clients to find one that resonated with them. After finding one each, we shared and discussed them, before picking one to do an improvisation on. At the end of the session people took their whakatauki with them. I noticed throughout the following week, that many people had put their whakataukī up on their wall, and when asked would quote it. I feel that being able to solidify this transfer of information both with music and resourcing was important to the success of this intervention.

Space was also affected by the ability to facilitate people working in smaller groups or spaces within the larger therapeutic space. This was coded as 'Spaces within spaces' and featured eight times through five sources. Being in environments where there was the ability to move into sub groups allowed individuals who were shy, paranoid, or taking longer to achieve a task to break away while still being around the group. When this was not able to be facilitated people would often appear disappointed when they couldn't achieve a task as quickly as their peers, or would give up faster if there wasn't an appropriate break away space for them.

These problems could in part be resolved by modifying or selecting the therapeutic space which was coded under the node 'Me or clients modifying or selecting a space to work in' in which nine references were found across nine sources. By selecting spaces with breakaway areas or moving furniture and objects in a way that showed that these areas were available as an option, clients were better resourced to find spaces within the main therapeutic space that suited their individual therapy within the wider group context. When 
doing individual work, I would make an effort for clients to be able to choose or modify the space. Some clients would choose to work in public spaces, while others felt more comfortable within more private spaces, where they could share more deeply about their connections to instruments, or feel less inhibited when playing things that were unfamiliar.

Under the topic 'Focusing on the therapeutic relationship and being open as a therapist' there were five codes titled 'Being honest about client progress, facility protocols and professional limitations', 'Seeking and acknowledging connections with clients', 'Sharing belief about Te Ao Māori knowledge in relation to taonga pūoro', 'Sharing stories about personal connection to kaupapa' and 'Using client rhetoric or humor where appropriate'.

The highest referenced code was 'Sharing stories about personal connection to kaupapa' which was coded eleven times across eight sources. To me, honesty feels key to therapy work. Throughout all three cycles, I found that when I was open with clients it helped to encourage them to be open with me which helped to improve the depth and effectiveness of the work. The safest way to engage in this deeper work was within individual sessions.

\section{Vignette Seven}

Sharing stories about personal connection to kaupapa

Example one - Alexa

$06 / 08 / 2018$

On an occasion where Alexa had been particularly distressed, she and I decided to have a session learning about taonga puoro. Alexa had an interest in drawing and would request to draw certain instruments after she had learnt about them and played them. We continued this way for a while, which was effectively distracting her from her previous anxieties while allowing her to do something that she was comfortable with by drawing the instruments.

Alexa would request kōrero on the different instruments which helped her to remember how they were played. After a while, she asked "Do they have names?" 
and she giggled. "Do you mean the kinds of instruments, or the instruments themselves?". She said "the instruments themselves". I paused to think about how in depth to go, "Do they... have names?" she asked again. I picked up a small kōauau made from the bone of a bird. "This one is called 'koha', it was made for me by my stepdad, the bone was found by my Mum so it was a special gift. Koha is also my brother's name... and to me, this instrument is spritely, light, young, joyous. All things that I think of when I think of him". She smiled, she asked if she could hear it and I played it for her. She said she heard what I meant about the sound. She said "Is he... still alive?" I told her no. She asked "Do you still remember him?" I told her yes, and that we believe in whakapapa, in attributes being genetic... I talked about knowing his personality and seeing those attributes in this special instrument and within myself and my family. She smiled at this, and said it was good I had that connection. She then mentioned it was her daughter's birthday in a few days. I asked her what she was like and she described a tomboy, full of life who loved drawing. She told me that she was coping so well, and that she is very resilient. Again, we talked about whakapapa and how maybe that's where her resilience comes from... and that maybe that was within Alexa too. She agreed.

I am first to admit that sharing information like this can be a challenging move to make. But as someone who is comfortable talking about this part of my life, I felt that it was safe to talk with Alexa in this way. By doing so, she was prompted to share deeper stories from her own life and we were able to link our shared korero back to te ao Māori and to use our conversations therapeutically. Having taonga there as a gateway into these deeper kōrero helps to ensure safety.

Through the use of these stories, I would often share with clients philosophy from Te Ao Māori including belief in concepts such as wairua and mauri. This was coded under 'Sharing belief about te ao Māori knowledge in relation to taonga pūoro' with four references from three sources. Being able to explain music, mental illness, and the connections within the two within a Te Ao Māori way helped to strengthen the connections that taonga pūoro had with the wider kaupapa of mental health. During this cycle, our facility was without a kaumātua, and suddenly I found myself along with other Māori staff going beyond our usual duties to make sure the needs of Māori clients were met. I found that it was important to be able to confidently voice my knowledge and beliefs, so that I seemed 
approachable about this which encouraged people to seek help when needed. This approach helped me to connect with many clients and to allow the use of taonga pūoro within therapy to unfold in a natural way.

Through allowing my philosophies to be visible, as well as building whakawhanaungatanga with my clients, I was able to build rapport quicker than I would have otherwise. The seeking of these connections was coded under 'Seeking and acknowledging connections with clients' with five references coded from five sources. Being open to sharing where my tribe and hapu are from allowed me to build rapport with people quickly and showed an element of trust while still protecting the relationship with the client. Seeking connections also included interests, achievements and beliefs. This was especially used with tauiwi clients who did not have iwi-based connections. As a pale Māori, being able to acknowledge iwi connections appeared to help other Māori clients engage, especially with regards to taonga puoro. Using the self in therapy to be able to put like with like and bond with clients, helps to build strong therapeutic relationships and is akin to the concept of 'being with' as is used in HMT (Heidegger, 1962).

Another important way to build rapport for stronger therapy was by use of client humor and rhetoric which was coded under 'Using client rhetoric or humor where appropriate'. I am privileged to come from a diverse background, and through the process of my training I have realized that my ability to use client rhetoric that is a part of my own language is a strength within therapy in regard to building rapport with difficult clients. I also found that the kaupapa can be seen as quite serious by some people, and in many ways, it is. Having an element of humour helped people feel more at ease and comfortable with attempting to play the instruments and made the atmosphere feel more supportive.

Within this work and the depth that this cycle explored, there was a strong need for honesty towards clients. This was coded under 'Being honest about client progress, facility protocols and professional limitations' with four references across three sources. As part of my personal development and sustainability as a therapist, I have learnt that I am incapable of fixing every problem with music. Accepting this, and then communicating that to clients allowed them to see me as an honest person, which improved my therapeutic relationships while protecting both myself and the client from being in situations where a health worker was attempting jobs outside of their jurisdiction 


\section{Cycle Three: Conclusions and Directions for Final Model of Practice}

As I have reached the end of my three cycles, I feel that it is important to look back across the findings from all three cycles to create a model for use in taonga puoro based music therapy, within the mental health context. I feel that there are some clear themes that have emerged throughout all three cycles that are of high importance to the authenticity and success of this mahi. I perceive these themes to be; use of narrative, depth and interconnectedness of therapy, self-determination in therapy, personal power, the natural and therapeutic environment, and spirituality. When I picture these elements, I picture them as six pou in a circle, with therapy being conducted in the centre.

By creating this model, I am aiming to create a resource for taonga puoro players and music therapists to use within their work, which will hopefully strengthen connections and understandings within the disciplines. This model will also be a more usable resource than this exegesis in its entirety, making it more accessible to our own communities as is part of the values of Kaupapa Māori research. 


\section{Developing a Model of Practice}

In order to keep with a Kaupapa Māori research ethos, I aimed to create useable model that will serve to benefit Māori. This resource has been developed through looking retrospectively at the findings from all three cycles of action, and finding themes that I view as crucial to the kaupapa across the work. In keeping with Kaupapa Māori, and to give further depth to the work, I have also provided a visual model where the six pou are represented, as well as the therapeutic space in the centre, 'Te Kauwhanga Whakahaumanu'.

The illustrated pou play tribute to toi Māori and are based on stylized pou, including tributes to other elements of toi Māori such as whakairo or carving, raranga or weaving, and tukutuku or lattice work. Symbols from te ao Māori such as Kawakawa, a plant used heavily in rongoa Māori or Māori medicine, mana wāhine which acknowledges the strength and value of Māori women, the kōkako, a bird that has influenced much of taonga pūoro, and the koru which symbolizes a variety of concepts within te ao Māori including new growth and peace have also been used.

\section{Nga Pou e Ono - The Six Supports}

Nga Pou e Ono is a model of six 'pou' or 'supports' that create the foundations for success within taonga pūoro based music therapy. It is to be noted that all the pou interlink, and that some elements of therapy or techniques may come under more than one pou, much like Kenny's 'Holographic Model' which served as an inspiration for this work. I have chosen the image of pou as I believe they are a symbol of toi Māori and mana Māori. I have also chosen them for the symbolism they represent with how they penetrate into the foundations from which we all stem, allowing us to acknowledge the importance of environment, whakapapa and depth within a Māori world view. I imagine these pou as a physical space when conducting or planning therapy, with the six pou in a circle with the therapist and clients at the center, using their music to mihi to the important aspects that are 
fueling their healing; creating a symbiotic relationship where the pou both give strength to and receive strength from the clients.
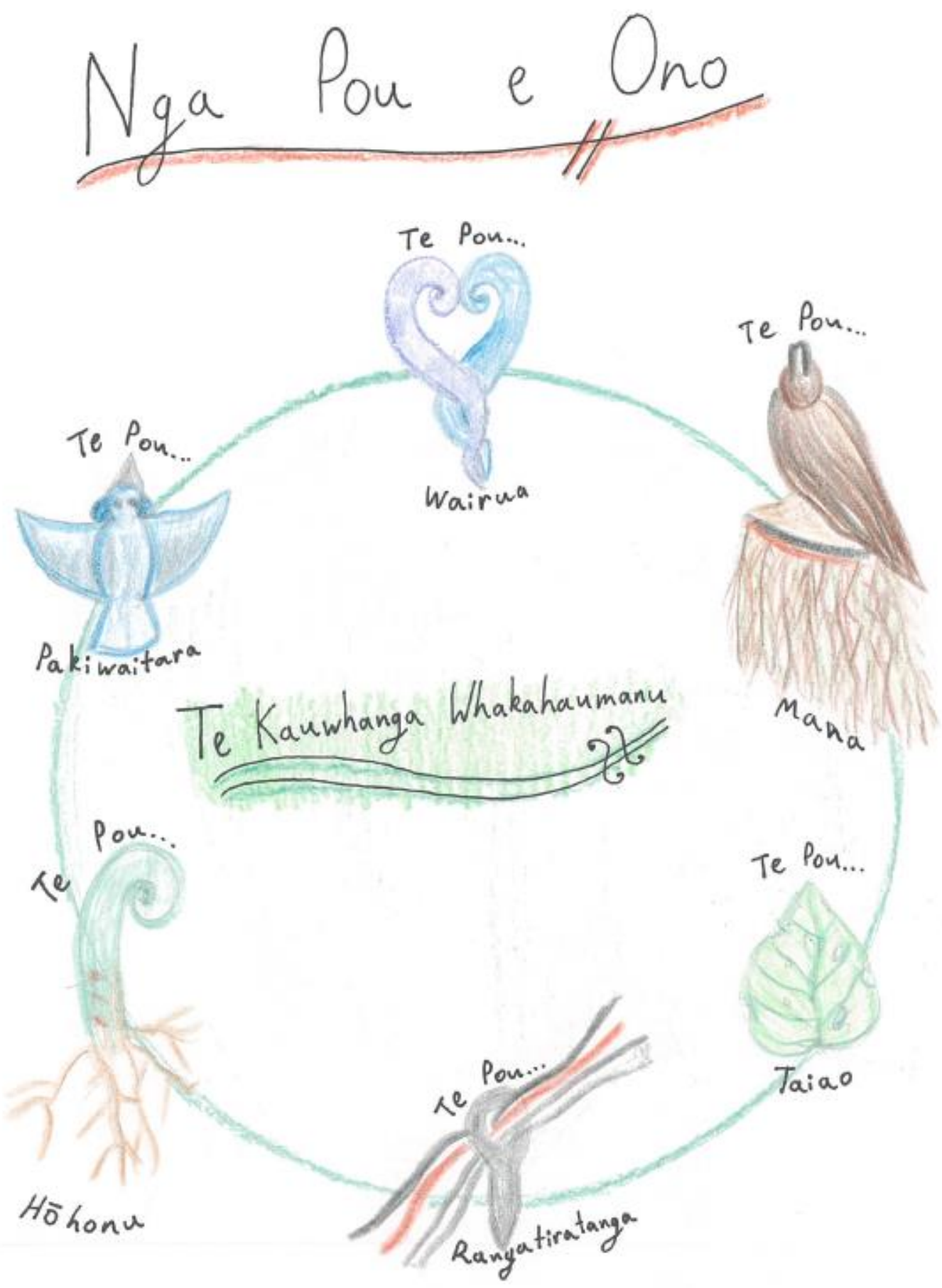


\section{Te Pou Pakiwaitara - The Support of Narrative and Story Telling}

This Pou represents the importance of narrative within therapy, and how kōrero can be used to strengthen the therapeutic relationship, instill value in the work, create a culture of sharing, and to reframe and emphasize the positive experiences of clients. As Māori we are natural orators; we use our kōrero to weave connections with others and create connections between people, places and objects. Being able to reweave the whariki is an important part of the taonga puoro revival and is equally important within therapy. Narrative helps clients to see the value of the instruments and learning the whakapapa of the instruments helps clients to establish parallels within their lives. By sharing kōrero as a facilitator, one can create a culture of sharing where clients feel compelled to share positive stories from their own lives in relation to the kaupapa, which can be emphasized and given deeper value through sharing and exploration of these stories within music. By engaging in practices such as mihimihi, we learn who our clients are, and we share who we are in relation to what they share. From there, we are able to enter into a space of partnership within therapy and puoro. 


\section{Te Pou Rangatiratanga - The Support of Self-Determination}

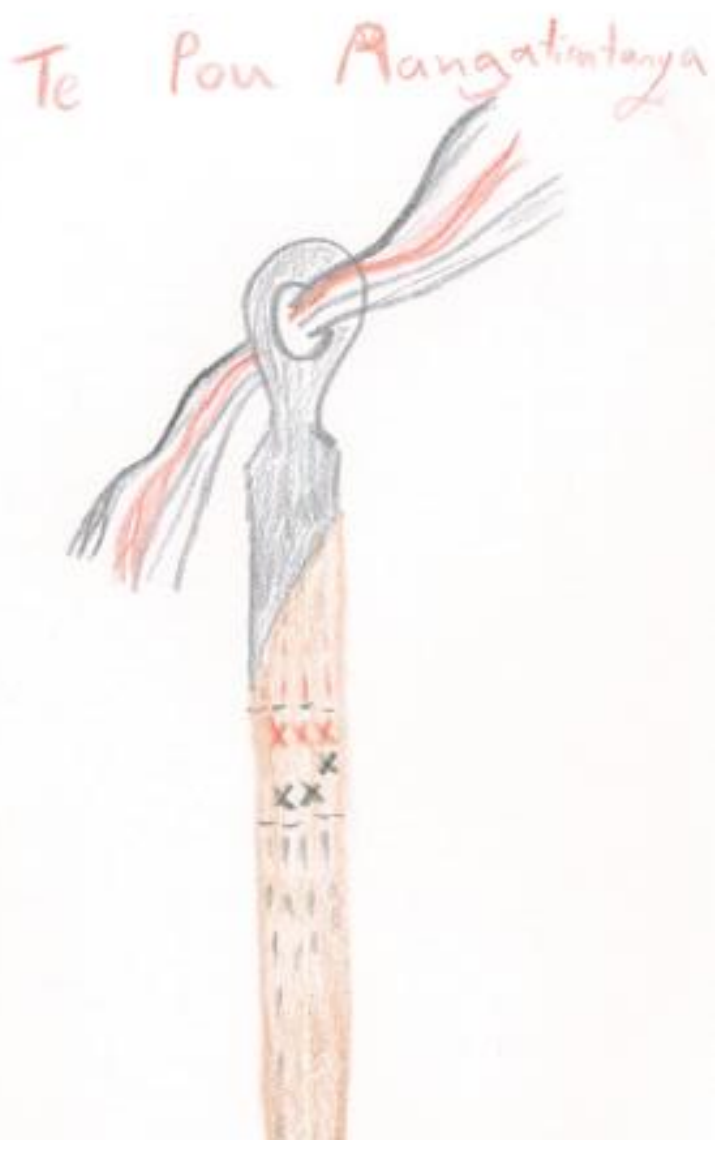

This Pou represents the value of a person-centered approach, and client autonomy within therapy. Tino Rangatiratanga describes the rite of Māori to have self-determination, autonomy and power. Within therapy, I see rangatiratanga as clients being able to choose what happens within therapy, and what directions the group takes. In my experience, this was represented through clients creating their own rituals within therapy, as was discussed by Kenny. Within individual therapy, clients engage in ceremonies around the instruments of their own invention, as inspired by the kōrero that we have around the instruments. 'Te Pou Rangatiratanga' also involved sustainability, in terms of clients being able to sustain their playing on their own after discharge if desired. This is achieved by supplying clients with resources and opportunities to craft and play outside of the unit, as well as having instruments within taonga puoro that are easily accessed in the natural environment such as tumutumu. Clients being able to set their own goals is also important for this pou, as clients who set their own goals and have their skills valued are more likely to engage with the kaupapa and to use it as part of their healing. 


\section{Te Pou Mana - The Support of Personal Power}

This Pou interrelates with 'Te Pou Rangatiratanga'; focusing on the fact that clients are complete, whole beings already when they come into the therapeutic space, a concept from Kenny (1989), and looking at how we can nourish this mana. Making sure that everyone in the room feels welcome and capable is crucial to working with the mana of clients. A tool used to achieve this is levelling; which involves using a large range of instruments from the whanau taonga puoro to make sure that all skill levels and strengths were catered for so that each client can feel capable and have a musical voice. It is also important to value all skills that clients wish to contribute to the group. If a client comes to me with a story, or a drawing, or wants to clean the instruments after people played, these are all valued with the same acceptance and importance as playing. When people feel that what they can give or wish to give is enough they often extend themselves to play or contribute more to the music and to their own therapy. This pou also encompasses the importance of nourishing the therapists own mana and reflecting on their own limits as a therapist. I sought bi-cultural supervision and looked to my own whakapapa to help give myself strength in therapy, and also worked to spend more time playing for my own hauora which helped me not only in my personal life, but helped my sustainability as a therapist. 


\section{Te Pou Taiao - The Support of the Environment}

This pou acknowledges the environment that the therapy takes place in, and the wider environment of the natural world. Within the kaupapa of taonga pūoro, Richard Nunns talks about the importance of being able to mihi to the environment. When clients are able to take taonga puoro back into natural surroundings, it helps to deepen their therapy and ground them within their landscapes and music. However, this is not always possible within the hospital setting. In these cases, taonga puoro can be used to create soundscapes that pay tribute to the natural world, selected by clients. This helps clients to feel as if they were in a more natural space, and to connect with environments that were important to them when they are not able to physically be there. The physical environment for sessions is also important. Natural lighting and having an open space assists people to feel welcome and to want to be in the therapeutic space. By following tikanga, such as laying the instruments on a cloth on the table, and not having food within the environment, people feel that there is a sense of having a sacred space in which it was safe to share and experiment with music. 


\section{Te Pou Hōhonu - The Support of Depth}

This pou acknowledges the importance of depth within therapy. This can be seen through clients being able to access and appreciate taonga puoro from all aspects. As a facilitator, this means being able to work with clients strengths and accepting whatever they can give to the kaupapa, as well as being able to view taonga puoro as a holistic medium and art form. This pou also helped me to realize the importance of going deeper within therapy to discover positive memories and attributes in clients that they could then see as valuable within their identity. This often involves talking about whakapapa and linking it to taonga puoro, in which clients are able to admire strengths within their whakapapa and see those reflected within themselves. Hōhonu, or 'depth' also meant clients being well informed about taonga puoro and being able to create instruments, play instruments, listen to puoro, and be good advocates themselves for the kaupapa. Having depth within taonga puoro knowledge helps clients to see the value of taonga puoro within their own lives, and helps them to value their skills and to see how they can contribute them to the kaupapa. 


\section{Te Pou Wairua - The Support of the Spirit}

This pou pays tribute to the importance of spirit within therapy and acknowledges that many people see this mahi as one of a spiritual nature. Wairua is a concept that is difficult to define, but I have often had it introduced to me as the spirit that is created when the waters of our two parents combine. Acknowledging wairua allows us to acknowledge the unique identities within groups, as well as nourishing clients within individual work. 'Te Pou Wairua' values meeting kanohi to kanohi and seeing people as inherently whole and knowing that they have potential to feel complete within themselves. Objects themselves can also possess wairua and mauri, and acknowledging the relationship that people have with these treasures helps to nourish the wairua of the individual. Initially, I was hesitant to incorporate wairua into sessions. But upon introducing clients to models such as Te Wheke and Te Whare Tapa Wha, the clients themselves showed interest in investigating the concept. I have also had it explained to me that spiritually in Māoridom can often be thought of as acknowledging our origins from the environment, which often came to the fore within therapy with people discussing experiences such as being within nature or taking time to think of tūpuna as being spiritual experiences. When spirituality was seen in this way, people of all faiths were able to perceive the concept of wairua as unthreatening to their core beliefs. Allowing all spiritualities to exist spontaneously and be valued within therapy. 


\section{Te Kauwhanga Whakahaumanu - The Central Space of Rejuvenation and Therapy}

'Te Kauwhanga Whakahaumanu' is the space in the centre of our circle of pou, in which we conduct our therapy. In this space we are protected by our six pou, and we are able to mihi to each pou, acknowledging their importance within therapy. 'Te Kauwhanga Whakahaumanu' is presented as being on the whenua which serves to pay tribute to the importance of the land and turangawaewae to Māori. Papatūānuku sustains us, and in return we respect and care for her, as we do in therapy when creating client-therapist relationships built on mutual respect and understanding. This space also pays tribute and can be compared in many respects to Carolyn Kenny's 'Field of Play'(1989). Kenny describes the 'Field of Play' as a "space of experimentation" where issues, significant feelings, values and thoughts can be expressed. This can only occur after safety has been established throughout all other aspects of her 'Field of Play' model. In the same way, in order for Te Kauwhanga Whakahaumanu to benefit us in therapy, we must first acknowledge our six pou and be aware of the reciprocal nature of nourishing taonga puoro as it nourishes us. 


\section{Discussion}

This research indicates that in order for taonga puoro to play an effective and important role within music therapy, they need to be fully integrated into the practitioner's practice and ideally within the wider values of the facility. This is not easy to achieve, and like much of te ao Māori, it is not something we either have or do not have, but rather a goal we are always working towards. I feel that I am constantly working to further develop my relationship with my six pou, to understand more about what they mean and to find the deeper meanings they have below the surface. This is more than something to be achieved, it is a way of discovering and a way of working to constantly evolve and better one's practice both within te ao Māori and within te ao Pākeha. As was stated by Rollo (2013), by working to decolonize our therapies, we are also working to decolonize ourselves as a people. Melbourne and Nunns (1991), and Thomas and Nunns (2011) also state the value of this, with Nunns (2001) describing how by using taonga puoro in a safe and thorough way, we are able to help not only ourselves, but also the generations that come after us, by paying tribute to the ones who have come before. As in humanistic approaches to music therapy where through working with clients through partnership which is a principal of our treaty in its' own right, we are able to heal both individuals and through that the communities they are from (Durie, 1994; Heidegger, 1962).

The integration of taonga puoro therefore implies a need to understand the wider te ao Māori; something that cannot be segmented for our own purposes and uses. But every facet of it is a possible door to be opened into our world. When using taonga puoro in my practice, it felt natural to take time to explain the whakapapa of these instruments and to use a te ao Māori world view to show their value. On occasions where people began using the instruments before I had time to work with them properly, the value they gained from the instruments was not as deep and didn't seem to affect the wairua in the same way. It felt to me that possessing an instrument and bringing it out to show people at some point during therapy wasn't enough to give the experience the value it deserves. But rather taking an approach where the therapist comes to therapy with an attitude of "You have value, and so does this, I want to share it with you" and by doing so engaging fully within te ao Māori, allowed the therapeutic relationship to flourish. In my view, it is not enough to have the instrument present and show the client how it is physically played. It was important for the client to know where the instrument fitted in to the larger world of te ao Māori, and for them 
to feel a sense of responsibility in being a part of the wider kaupapa. However, Fletcher, Green, Macdonald and Hoskyns (2014) found that a client found the meaning of the instrument, without hearing the kōrero around it. In many ways, this pays tribute to our innate knowledge as Māori. Their project too followed tikanga and worked with Māori to create a wholistic experience that was seated comfortably within te ao Māori. In Hodgson's work (2014), I was initially struck by how a Māori worldview influenced all of his practice, by acknowledging concepts such as wairua and mauri with both Māori and Tauiwi clients. But by the end of my research, I have realized that I too see the work this way. This shows potential for how a Māori world view is inseparable from our work as Māori and shows how when working with Māori kaupapa such as taonga puoro, it adds depth to the work to acknowledge and own this worldview as a taonga toku iho, a treasure passed down from our ancestors, for us to use to help others. Nunns (2001) comments too on how these instruments have "everything to do with the wairua", which is represented in both my findings, and that of Hodgson (2014). Niania, Bush, and Epston (2016) also discuss the interconnectedness of te ao Māori, citing concepts such as wairua and whakapapa as being integral to working with Māori therapeutically.

Wairua is a crucial aspect in the practice of Wiremu Niania, who has run nation-wide hui on the subject. When I attended one of these hui earlier this year, my heart was warmed by how many people were there because of their work with wairua, many of whom were workers in the public system. Acknowledging our view as Māori and being an advocate for the value of a te ao Māori world view in health is crucial for health workers within this sphere, as to increase the public awareness, accessibility, and understanding of te ao Māori within the health sector. Bowden (2015) writes how as a Pākehā therapist, he too has found value in learning the ways of te ao Māori, and how doing so has changed his practice for the betterment of all his clients. This is something I found within my own work, as both Māori and Tauiwi clients found solace and engaged well with taonga puoro in therapy. I found that unlike I had previously thought, the way I viewed Māori and Tauiwi patients was through the same te ao Māori lens, using concepts like wairua and whakapapa and looking at any raruraru in a systemic way. I found this approach deepened the way I worked with clients, and was as successful for Tauiwi, as it was for Māori

This research too has shown that the work of an Indigenous therapist, is not the work of one, but of many. As cited by Nunns (2001) in his experiences with kaumātua around Aotearoa, 
this work is one based around healing and we run a risk of losing the therapeutic applications of nga taonga puoro if we do not consult with our kaumātua and experts. We are able to do the work we are doing today because of our tūpuna, because of those who kept the knowledge alive during the times of the Tohunga Suppresion Act, and because of the revivalists Melbourne, Nunns and Flintoff, and those that have continued on with their kaupapa with open hearts and minds to share with the next generation. Hodgson (2014) also discussed the importance of consulting with kaumatua within his practice, as did Kahui (2008) who commented on the grounding effect this had on his practice. For myself as a researcher, the research of Kahui and Hodgson were invaluable to my own work, and I feel privileged to be able to walk the path that they have walked as Māori music therapists.

Something that featured with both Māori and Tauiwi clients was the value of taonga puoro in changing the environment. As Māori we feel that we are direct descendants of the whenua, of Rangi and Papa, and our environments are crucial to our sense of self and survival. Bush, Niania and Epston (2016) discuss the importance of this, and cite this as how our world is woven together and all interconnected; through te taiao, our environment and mother. The sounds of taonga puoro come from our natural world, allowing us to recreate the sounds of places that build our identity. Kenny (1989) also acknowledges the value of the environment to Indigenous peoples, and the way that we are in tune with our environments and the linkages of all things. In her work with Fraser (2012), the authors acknowledge the connectedness with the environment and the reciprocal nature of this relationship, something that also rings true within the kaupapa of taonga puoro. I found that when people are in places that they do not wish to be held, being given permission and a sensory way to leave this place to journey to their turangawaewae, or other places that give them peace, can be the most therapeutic intervention of all within this style of work. In many ways this is similar to what McIvor (1998) found with her investigations into Māori and the use of GIM, where music allowed her participants to undertake spiritual journeys through the mind while listening to music, some of whom did return to their turagawaewae within this process. Looking deeper into this, I feel that it is no coincidence that the mental health of our people began to suffer with the removal of Māori from our whenua, and within the second migration, as shown by Baxter (2008) and Cram, Smith and Johnstone (2003). Connection with whenua and turangawaewae is a crucial element of hauora, and in situations where this is not possible, taonga puoro can play a role of transportation. Nunns (2001) also acknowledges the role of taonga puoro not only to heal the people, but also to heal the environment, describing playing 
to a river in te Waipounamu, and a large piece of pounamu being unearthed in the process. The moments where clients were able to connect with te taiao in this way and enter into a reciprocal relationship with the whenua that supports them, were some of the most beautiful moments I experienced in therapy.

Throughout this work, I have experienced a struggle within myself over the connotations I see around the concept of healing, and healers, and how this word fits into both te ao Māori and within western music therapy. The word healing comes from Germanic origin, with the old English being 'hælan', meaning to "cure; save; make sound and well" (Etymonlie, 2018). As compared to the Māori word for healing 'whakaora' with 'whaka' being a prefix used to denote action or transform a word into a verb, and 'ora' meaning to " $b e$ alive, well, safe, cured, recovered, healthy, fit, healed" as well as "to survive, escape" and "to recover, revive" (Maori Dictionary, 2018). Within this translation, we still see parallels with the Germanic roots of the English translation. However, we also see more variation in the concept of whakaora, that acknowledges acts of working towards wellness, wellbeing, improving safety, and clients lives, rather than just serving to make them 'whole'. Within Carolyn Kenny's philosophy (1989), and indeed, within my own which is placed within te ao Māori, people are perceived as being whole beings when they enter into therapy. Not as individuals who need to be fixed, but complete beings who require their needs to be met and their mana honored, as is also found within HMT with the concept that humans are more than just the sum of their parts (Bugental, 1964). Through the word whakaora, we can see elements of this philosophy represented. I believe that when Māori speak of healing, we are often translating ourselves and are rather seeing this as 'whakaora'; a way to work with an individual to meet their needs to ensure that they are in wellness.

\section{Indigenous Applications and Limitations}

The model created from this work, 'Nga Pou e Ono' has been designed for music therapists looking to incorporate nga taonga puoro within their practice with a particular focus in mental health, but I feel that this model also has value for other clinicians such as counsellors, psychologists and other health workers who wish to practice with a te ao Māori focus. When sharing this model with other Māori clinicians and mentors during its development, the majority of my peers said that each pou was part of their larger world view as Māori, however when shared with Pakeha clinicians and mentors, they were more 
surprised by the elements included within the model, and could see its use for the work that they do with Māori clients. I feel that Pākeha practitioners would benefit from this model especially, as it explains through the eyes of Māori how we see this work and how it interconnects with all things in our world.

Through the action research process, I have also created a programme for using taonga puoro in group music therapy. This program has been developed to embody the six pou and through this weave together elements of te ao Māori such as legends, whakatauki, sense of place, environment, karakia, crafting, and whakapapa within the use of taonga puoro in music therapy. This programme, and similar ones that other practitioners may develop using 'Nga Pou e Ono' and this research, would also have potential in other populations such as family therapy, special needs, youth mental health, and the takatāpui community. Because of the atonal possibilities of the instruments, clients are able to play and improvise together even at early stages of their playing knowledge. As there is a range of instruments there are also a variety of levelling opportunities for clients of various abilities and needs to be able to contribute to the kaupapa, and to add their part to group music in a way that all contributions are valued, regardless of the difficulty or simplicity of the playing.

In terms of limitations, the action research process provides challenges as the research can only use data created organically within sessions. However as we engaged in mihimihi and poroporoaki, I was able to gather data that reflected how people felt about the sessions. Though it is to be acknowledged that as they were sharing this information within the group and with me present that they could have expressed what they thought I wanted to hear. But in seeing their involvement, and how people would return to my group each week helped me to see that this was something they found valuable to their recovery and worthy of their time. However, if I was to undertake further research I would highly consider using a participatory action research-based approach to improve the accuracy and depth of data.

Because of the nature of the ward, there were some instruments and activities that clients were unable to use or participate in because of risk. Instruments such as the purerehua which was often requested by clients, wasn't safe to use in the majority of situations. Therefore it was hard to use the full scope of taonga puoro within therapy. However, I was able to find ways to safely work towards using some of these instruments, by using instrument creation and design, pre-recorded music, and finding similar instruments to ones 
that were considered dangerous either spiritually or audially depending on the needs of the client.

The ward in which the research took place involves a range of different therapies that are used to provide clients with a package of care to support their recovery. Because of this it is difficult to tell what effect any single therapeutic element or intervention has had on a client. Of course, clients themselves give feedback, which has often been in favour of the taonga puoro group. However it is important to acknowledge that taonga puoro based music therapy was successful as part of a range of interventions.

\section{Recommendations}

Through the growing of my practice, and through the opportunities I have been given to work with other populations including children, and in a prison context, I can see that both mental health and other populations have potential for success using taonga puoro based music therapy. As my knowledge of the instruments deepened, I realised more and more that the instruments have uses far beyond what I initially thought. I feel that further investigation into the therapeutic use of the instruments, both inspired by traditional knowledge, and by the needs of Māori, would benefit both the discipline, and our people; which I believe is crucial to the authenticity and ethics of this kaupapa. I am excited to undertake further research into this field in the near future, as through this research I feel that I have found something that enables me to give back to a culture that has given me so much, and to help others through honouring the ways of our ancestors in te ao hou. 


\section{Summary of Discussion}

This research has assisted with creating a music therapy model, 'Nga Pou e Ono' which can be used to resource music therapists and other health workers within the use of taonga pūoro in music therapy. It was found that within the facility, it was crucial for taonga pūoro to be embedded into the wider culture of the facility, as well as for a te ao Māori worldview to be embraced by the therapist across all work. The healing powers of nature and the value of clients being able to enter into reciprocal relationships with the environment within their therapy has been explored. It has been acknowledged that the word healing is a marked term with different connotations between te ao Māori and te ao Pākehā, and that sometimes terms such as this are lost in translation. This research has been inspired by the work of Kenny and Fraser (2012), as well as the work of Māori music therapists such as Hodgson (2014) and Kahui (2008), and revivalists such as Melbourne (1991), Flintoff (2004) and Nunns (2001) and the generations of players that have come after them and supported this kaupapa. Limitations were noted including the limitations of action research, the difficulty to assess the individual effect of taonga puoro on clients recovery within a wider therapeutic program, and the limitations of bringing outside resources into a psychiatric ward. Further research has been recommended on the topic of taonga puoro in music therapy, citing the use this may have for further populations including prison work, children, and family therapy. 


\section{Conclusion}

This study was focused on developing my use of taonga puoro within my practice as a music therapy student within an acute mental health facility. This study utilized a qualitative design, and the research used a self-reflective action research methodology, with Kaupapa Māori Theory as its' theoretical standpoint. Over the course of three action research cycles, I observed and developed different themes that I found within the analysis of the work by undertaking action plans informed by the analysis of the research. These action plans amongst others included investigating the use of story within taonga puoro based work, client creation of instruments, forming real world connections with the kaupapa, and developing and acknowledging the therapeutic and physical environment. Data was collected from my reflective journal and clinical notes, and analysed thematically between each cycle to form conclusions on the action plans, and to anticipate which action plans should be included in the next cycle.

The results from all three cycles was used as inspiration to create a model outlining a circle of six key 'pou' or 'supports' within taonga pūoro based music therapy. These six pou were 'Te Pou Pakiwataira - The Support of Story Telling', 'Te Pou Rangatiratanga - The Support of Self-Determination', 'Te Pou Mana - The Support of Personal Power', 'Te Pou Taiao - The Support of the Environment', 'Te Pou Hōhonu - The Support of Depth', and 'Te Pou Wairua - The Support of the Spirit' with the space in the centre of the circle of pou, 'Te Kauwhanga Whakahaumanu - The Space of Rejuvenation and Therapy'.

It has been acknowledged that this research has been made possible because of the work of our tūpuna, as well as revivalists of taonga puoro, and the modern players who have supported this kaupapa. I have acknowledged the limitations of the self-reflective action research process, and have expressed a need for more research in the area of taonga puoro within music therapy, especially in other populations in order to create a more holistic model and resource; something that I see within my future and that I am excited to undertake. 


\section{References}

Aarø, L. E., \& Stige, B. (2011). Invitation to community music therapy. London: Routledge.

Argyris, C. Putnam, R. \& Smith, D. (1985). Action Science: Concepts, methods and skills for research and intervention. San Francisco: Jossey-Bass.

Baker, F. (2007). Enhancing the clinical reasoning skills of music therapy students through problem based learning: An action research project. Nordic Journal of Music Therapy, 16(1), 27-41.

Barry, W. (2013). Quality and the Art of Researching Your Own Practice: An Inquiry into Values and the Dangers of Assumptions and Mind Reading. Presented at Researching Our Own Practice, Liverpool Hope University.

Baxter, J. (2008). Mãori Mental Health Needs Profile: A Review of the Evidence: Summary. Wellington:Te Rau Matatini.

Bazeley, P., \& Richards, L. (2000). The NVivo qualitative project book. Thousand Oaks: Sage.

Beaglehole, E., \& Beaglehole, P. (1947). Some Modern Māori. Wellington: New Zealand Council for Educational Research.

Best, E. (1925). Games and pastimes of the Maori: an account of various exercises, games and pastimes of the natives of New Zealand, as practised in former times; including some information concerning their vocal and instrumental music. Christchurch: Whitcombe and Tombs Ltd.

Bowden, A. (2015). Culturally-based impacts on a psychotherapy practice in Aotearoa. The New Zealand Journal of Music Therapy, 13, 33-50. Retrieved from https://search-proquest-com.helicon.vuw.ac.nz/docview/1897698598?accountid=14782 
Bugental, J. F. (1964). The third force in psychology. Journal of Humanistic Psychology, 4(1), 19-26.

Bunt, L., \& Hoskyns. S. (Eds.). (2002). The handbook of music therapy. Hove: Brunner-Routledge. 2012.

Castleberry, A. (2014). NVivo 10 [software program]. Version 10. QSR International;

Cram, F., Smith, L., \& Johnstone, W. (2003). Mapping the themes of Maori talk about health. New Zealand Medical Journal 116:1170

Durie, M. (2017). Māori health models - Te Whare Tapa Whā. Retrieved October 1, 2018, from https://www.health.govt.nz/our-work/populations/maori-health/maori-healthmodels/maori-health-models-te-whare-tapa-wha

Durie, M. (2004). Understanding health and illness: research at the interface between science and Indigenous knowledge. International journal of epidemiology, 33(5), 1138-1143.

Durie, M. (1994). Whaiora, Maori Health Development. Auckland: Oxford University Press.

Durie, M. H. (1985). A Maori perspective of health. Social science \& medicine, 20(5), 483-486.

Elwafi, P. (2008). The Maori Ways of Traditional Healing: Tina Fraser interviewed by Paige Robbins Elwafi. Voices: A World Forum For Music Therapy, 8(3). doi:10.15845/voices.v8i3.422

Edwards, J. (2016). The Oxford handbook of music therapy. Oxford, UK: Oxford University Press.

Etymonlie. Heal (V.). (n.d.). Retrieved October 16, 2018, from https://www.etymonline.com/word/heal

Fletcher, H., Green, C. D., MacDonald, M., \& Hoskyns, S. (2014). Raranga wairua: Creative cultural collaboration in an infant child \& adolescent mental health service. The New Zealand Journal of Music Therapy, 12, 87-105. 
Flintoff, B., Melbourne, H., \& Nunns, R. (2004). Taonga Puoro. Craig Potton Publishing: Nelson.

Flintoff, B. (2004). Singing Treasures. Nelson: Craig Potton Publishing.

Fox, G., Green, M., Martin, Peter J, \& Ebooks Corporation. (2007). Doing Practitioner Research. Australia: Ebooks Corporation Limited.

Freire, P. (1970). Pedagogy of the Oppressed. New York: Herder \& Herder.

Geuss, R. (1981). The idea of a critical theory: Habermas and the Frankfurt School. Cambridge: Cambridge University Press.

Heidegger, M. (1962). Being and time. 1927. Trans. John Macquarrie and Edward Robinson. New York: Harper.

Heron, J. (1996). Cooperative Inquiry: Research into the human condition. London: Sage.

Hodgson, N. (2014). He oro hauora: How do kaupapa Māori models of health relate to my music therapy practice in an adolescent acute mental health unit? Unpublished Master's Thesis. Massey University \& Victoria University of Wellington.

Horton, R. (2006). Indigenous peoples: time to act now for equity and health. The Lancet, 367(9524), 1705-1707.

Hudson, M. L., \& Russell, K. (2009). The Treaty of Waitangi and research ethics in Aotearoa. Journal of Bioethical Inquiry, 6(1), 61-68.

Hudson, M. (2004). He matatika Maori: Maori and ethical review of health research. Masters Dissertation, Auckland University of Technology. 
Jenkins, K., \& Pihama, L. (2001). Matauranga wahine: Teaching Maori women's knowledge alongside feminism. Feminism \& Psychology, 11(3), 293-303.

Kahui, D. J. (2008). A cultural approach to music therapy in New Zealand: a Mãori perspective. Unpublished Master's Thesis. Massey University \& Victoria University of Wellington.

Kenny, C., \& Ngaroimata Fraser, T. (Eds.). (2012). Living Indigenous leadership: Native narratives on building strong communities. Vancouver: UBC Press.

Kenny, C. (2014). The Field of Play: An Ecology of Being in Music Therapy. Voices: A World Forum For Music Therapy, 14(1). Retrieved October 1, 2018 from https://voices.no/index.php/voices/article/view/2245. doi:10.15845/voices.v14i1.737

Kenny, C. (1989). The field of play: A Guide for the Theory and Practice of Music Therapy. California: Ridgeview Publishing Company.

Kenny, C. \& West, T. (2017). The Cultures of Native Americans/First Peoples: The Voices of Two Indigenous Woman Scholars. In A. Whitehead-Pleaux \& S.A. Kim (Eds). Cultural intersections in music therapy: music, health and the person. 125-136. Dallas TX: Barcelona Publications.

Kingi, Te Kani R. (2011). Māori Mental Health: Past, Present and future. In T. McIntosh \& M. Mulholland, M. (Eds.). Maori and Social Issues. Wellington: Huia Publishers.

Komene, J. E. (2009). Kōauau auē, e auau tō au e! The Kōauau in Te Ao Māori. Doctoral dissertation, The University of Waikato.

Māori health models - Te Whare Tapa Whā. (2017, May 18). Retrieved October 1, 2018, from https://www.health.govt.nz/our-work/populations/maori-health/maori-healthmodels/maori-health-models-te-whare-tapa-wha

Lewin, K. (1946). Action research and minority problems. J Soc. Issues, 2(4): 34-46. 
Maori Dictionary. Whakaora. (n.d.). Retrieved October 16, 2018, from $\mathrm{http}: / /$ maoridictionary.co.nz/search?idiom $=\&$ phrase $=\&$ proverb $=\&$ loan=\&histLoanWords=\&k eywords=whakaora

McFerran, K., \& Hunt, M. (2008). Learning from Experiences in Action: Music in schools to promote healthy coping with grief and loss. Educational Action Research, 16(1), 43-54.

McIvor, M. (1998). Heroic Journeys: he taonga i kitea na te moemoea-a project exploring the use of therapeutic music and imagery with participants from the Maori culture. Annual Journal of the New Zealand Society for Music Therapy, 27-36.

McIvor, M. (1988). New directions inspired by the old: a pakeha looks at Māori chant. Annual Journal of the New Zealand Society for Music Therapy, 2-9.

Melbourne, H. (1991). Toiapiapi: he huinga o ngā kura pūoro a te Māori. Titi Tuhiwai. Wellington: Shearwater Publishing.

Ministry of Health. (2016). 2016 Health Survey. Retrieved February 13, 18, from https://minhealthnz.shinyapps.io/nz-health-survey-2016-17-annual-dataexplorer/_w_d975e0a1/\#!/explore-topics.

NiaNia, W., Bush, A., \& Epston, D. (2016). Collaborative and Indigenous Mental Health Therapy: Tãtaihono-Stories of Māori Healing and Psychiatry. London: Routledge.

Nunns, R. (2001). Te Ara Puoro: The pathway of sound. Voices: A World Forum For Music Therapy, 1(3). doi:10.15845/voices.v1i3.65.

Orange, Claudia. An Illustrated History of the Treaty of Waitangi / Claudia Orange. (2015). Web.

Palmer, S. (2005). Psychometrics: An ancient construct for Maori. New Zealand Journal of Psychology, 34(1), 44-51. 
Patterson, J. (1994). Exploring Maori Values. Australia: Dunmore.

Pohatu, T. W. (2004). Ata: Growing respectful relationships. He Pukenga Korero, $8(1), 1-8$.

Powick, K. (2002) Nga take matatika mo te mahi rangahau Maori. Maori research ethics: A literature review of the ethical issues and implications of kaupapa Maori research and research involving Maori for researchers, supervisors and ethics committees. Hamilton: School of Education, University of Waikato.

Priestley, M. (1994). Essays on analytical music therapy. Barcelona Publishers, Barcelona.

Rickson, D., Evans, A., Claydon, N. R., Dennis, P., Dovey, K., Francis, T. K., ... \& Dombroski, J. (2014). Active music. New Zealand School of Music; IHC New Zealand.

Robinson, S. T. (2005). Tohunga: The revival: Ancient knowledge for the modern era. Auckland: Penguin.

Rollo, T. M. (2013). Ma te wai ka piki ake te hauora. The New Zealand Journal of Music Therapy, 11, 51-80. Retrieved from https://search-proquestcom.helicon.vuw.ac.nz/docview/1503780683?accountid=14782

Smeijsters, H. (1997). Multiple perspectives: A guide to qualitative research in music therapy. Dallas TX: Barcelona Publications.

Smith, G. H. (1997). Kaupapa Maori: Theory and Praxis. Unpublished Doctoral Dissertation. Education Department: The University of Auckland. NOTE: Monograph, published by The International Research Institute for Maori and Indigenous Education.

Smith, G. H. (1990). ^Research Issues Related to Maori Education', paper presented to NZARE Special Interest Conference, Massey University, reprinted in 1992, The Issue of Research and Maori, Research Unit for Maori Education, The University of Auckland. 
Smith, L. (2005). Decolonizing methodologies: Research and Indigenous peoples. London: Zed Books.

Stige, B. (2012). Elaborations towards a notion of community music therapy. Gilsum NH: Barcelona.

Thomas, A. (2011). World Music is where We Found it. Wellington: Victoria University Press. (A First Encounter in New Zealand, Richard Nunns and Allan Thomas).

Wadsworth, B. J. (1996). Piaget's theory of cognitive and affective development: Foundations of constructivism. White Plains, New York. Longman Publishing.

Wenger, E. (1998). Communities of practice: learning, meaning and identity. Cambridge: Cambridge University Press.

Whitehead, J., \& McNiff, J. (2006). Action research: Living theory. Sage. 


\section{Appendix One: Facility Consent Form}

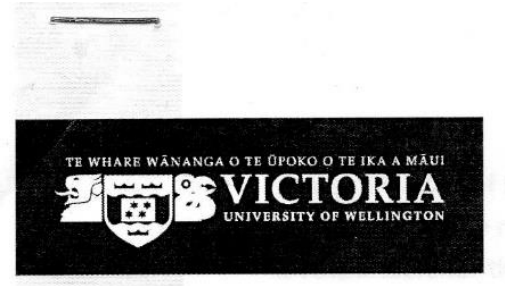

TE KŌKIT NEW ZEALAND SCHOOL OF MUSIC

VICTORIA UNIVERSITY OF WELLINGTON, PO Box 600, Wellington 6140, New Zealand

Phone +64-4-463-5369 Email music@nzsm.ac.nz Web www.nzsm.ac.nz

Dear

I am writing to ask for formal permission to undertake my research as a requirement for Masters of Music Therapy degree. As you know, I am currently completing a work placement at $\quad$ as a music therapy student. I am thoroughly enjoying being a member of the team at $\square$ and would like to thank you and the staff for making me feel very welcome and well supported in my work here.

One of the requirements of my qualification is an exegesis on an element of my practice. I am planning to write mine on my use of taonga pūoro in music therapy, which you have seen in action at 'Houmanu Rōpū'. My research question is, "How can l as a Māori music therapy student develop the use of taonga pūoro in my practice to support client recovery in an inpatient mental health setting" and is classified as self-reflective action-research for professional development. Meaning that the research focuses on my own development, rather than using clients as participants. Therefore, the research is low risk to clients as they are not directly involved within the study. If given approval from you, the facility will be anonymised in the research and individual clients will not be mentioned to a level of detail where they will be identifiable as to protect client, staff, and facility privacy and safety. Nevertheless, there is a tradition for student music therapy research dissertations in our school to include short illustrative vignettes of practice. I will be preparing information and consent forms for individual participants and staff, to invite one or two people to be involved and to consult with them for consent (using a third party) if this is deemed appropriate by you.

I have received approval from the New Zealand School of Music Post Graduate Committee, who advised; "The Postgraduate Committee considers this to be an excellent proposal. It is extremely well considered in terms of its contextual background and proposed research methodology. The timeline is exemplary and the document itself is very well-supported throughout with citations. Furthermore, it is beautifully presented and lucidly written. It's clear to us that Ruby is bringing a passion and artistry to this process. Extremely happy to approve!". I have attached a copy of my proposal if you would like a closer look at what I would like to achieve with this piece of work.

In short, my research aims to investigate the applications that taonga pūoro has within my work with both Māori and Tauiwi (non-Māori) clients within mental health to aid with recovery. I plan to use post-colonial theory as well as indigenous music therapist, Carolyn Kenny's 'Field of Play' theory to influence both my practice and action research. I was granted approval from the university on March $15^{\text {th }}$ to undertake this study. This research has been approved under an ethics template (Ethics Approval:22131 Master of Music Therapy Programme ethical template for student research in NZSM 526 undertaken as observational studies, theoretical or case study research or action research) by Victoria University of Wellington Human Ethics Committee. As my study is introspective I have been advised that would normally require no additional ethical approval. In accordance with normal ethical practice, I consulted with TWOM kaumātua, Flo Lawrence, and with experts in both the fields of music therapy and taonga pūoro.

This project has been reviewed and approved by the New Zealand School of Music Postgraduate committee. The VUW Human Ethics Committee has given generic approval for music therapy students to 
conduct studies of this type. The music therapy projects have been judged to be low risk and, consequently, are not separately reviewed by any Human Ethics Committees. The supervisor named below is responsible for the ethical conduct of this research. If you have any concerns about the conduct of this research, please contact the supervisor or, if you wish to raise an issue with someone other than the student or supervisor, please contact the Victoria University of Wellington Human Ethics Convenor AProf Susan Corbett, email susan.corbett@vuw.ac.nz, telephone +64-4-463 5480.

Thank you for your time in regard to my request, it would be much appreciated if you could reply by email to let me know if the facility can approve this research. If you have any questions, please contact me (rubymaehinepunui@gmail.com) or phone (0226133104), or my research supervisor, Associate Professor Sarah Hoskyns (sarah.hoskyns@vuw.ac.nz) or phone (0211009531).

Ngā mihi nui,

Ruby Solly

Music Therapy Student

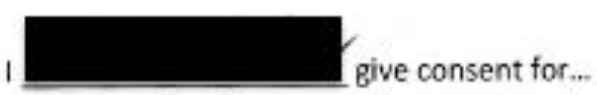

- Ruby Solly to use vignettes about her development as a music therapist while working with and its clients.

- I understand that all vignettes will be highly anonymised and that all clients involved in vignettes have been informed about the research taking place and the possibility of vignettes.

- I understand that this research will be published in an exegesis available from Victoria University. I understand that the facility itself will also be anonymised to further protect clients.

- I understand that the anonymised research data will be kept in a locked secure cabinet at the New Zealand School of Music care of Ruby's supervisor, Sarah Hoskyns, for a period of ten years. Upon which time it yill be destroyed.

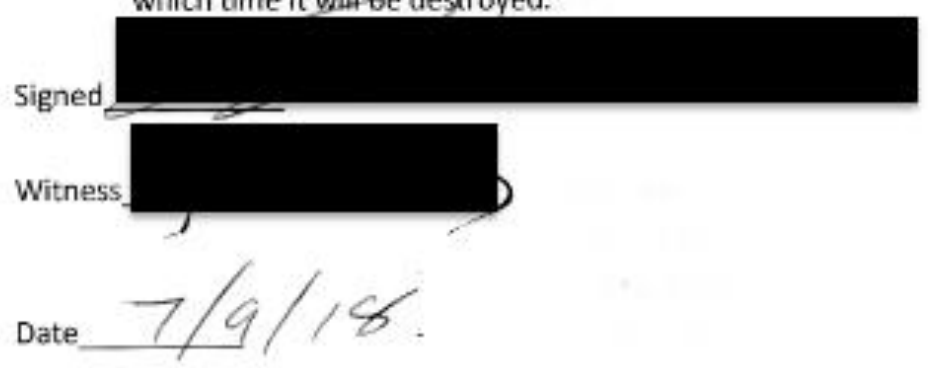




\title{
Appendix Two: Example of Reflective Journal
}

\author{
Friday $27^{\text {th }}$ July \\ Haumanu Rōpū \\ (Please note that all names have been changed, along with defining features, \\ diagnosis and gender where deemed appropriate, to protect client privacy).
}

The group today was based around whakatauki or proverbs. The group was held in The medium security ward in a table in the centre, I had laid out my gold cloth on the table and laid out the instruments upon it. Before the session began, Keriata came over to me and pointed at the poi awhiowhio; "I remember that one". I helped her to play it and encouraged people who were gathering to listen quietly to see if they could hear it. While Keriata played, another young man (Fabian) came over and sat down, he asked if he could touch the instruments and I agreed. He looked at several carefully and I explained each one. During this time, a young woman who is very unwell, Lily, entered the space with a bowl of cereal and a hot coffee. I politely asked her to move away from the instruments with her food, to which she agreed. I was being aware of the importance of keeping the space sacred in a way... tapu. Sometimes I feel conflicted about people touching the instruments before the group properly begins and we say karakia... but this time at the start where people feel they can explore without restraints can be really valuable. Some of the best engagement I've had with people who are difficult to engage has occurred in this time. During this time, Roimata comes over and puts her porotiti that she made at woodwork on the table next to the other instruments. It blends in seamlessly, I tell her this and tell her it's because she did such a good job, she smiles and walks away.

Soon the assisting OT arrives with the other interested clients, and we all sit down to begin. I ask if anyone would like to say karakia, and Keriata offers. She leads a long prayer where she acknowledges everyone in the group. Initially people seem uncomfortable but then they begin to smile as they are acknowledged... this was a lovely light moment, and for Keriata it seemed like something she was able to do confidently even though she was unwell which proved important for nourishing her mana and acknowledging her successes in recovery. 
After this I thanked Keriata, and gave a brief explanation of the instruments. Starting people off with porotiti as all but one group member hadn't been before. I set Fabian up with one, and he found it easy to keep the rhythm when I was helping the others, but once I moved away after only a few spins the porotiti would stop. He seemed slightly disheartened but keen to persevere. I asked if he wanted me to set it up again for him, but he was more eager to do it his own way. His father was there, and I saw the potential for the two of them to have a shared therapeutic experience. I gave the father a porotiti and worked with them to play, the father picked it up quickly, and then moved on to teaching Fabian. Fabian and his father stood just beyond a waist high room divider, which created a kind of separate space for them to work in. This allowed them protection from group judgement and space to have a moment to focus on their own work and relationship. Whenever I had a moment where the other group members were engaged, I would check in... about half way through the group Fabian said "I got it!" and he and his Dad were smiling. I thanked him for his perseverance and told him about the whakapapa of the porotiti.

I also set up Maggie, a woman who has had a long hospital stay with depression and self-harm, with a porotiti. She achieved it quickly, and the fact that it was easy for her made it seem not as impressive. As I had kept Fabian in a slightly disjointed space, she didn't get to see that for others, this could be difficult... however this did work to protect Fabian.

I reminded John of his koauau playing ability from his last admission. I found the two koauau that he had played last time and offered them to him, of which he chose the bone one. He lifted it to his lips expectedly, but was unable to produce a sound immediately, at which he appeared disappointed. I reassured him that it might take a while 'to get his groove back'. I then brought out some easier instruments, to make sure everyone had a base level of playing. We worked with tumutumu and the various hue instruments, while Keriata showed us her poi awhiowhio playing. Keriata's poi awhiowhio helped people to listen in and changed the atmosphere, creating calm... just like hine pu te hue does in the stories the group has been told.

I then suggested we do an improvisation around a whakatauki. I had a range of different proverbs on small pieces of paper that I put out on the table. I suggested we explore them and find one each that we liked. The group was tentative, but eventually they began sifting through proverbs. 
We each read out the ones we had chosen and talked about what they meant to us. We picked one about strength and perseverance and talked about what we could do to represent it musically. I suggested a strong beat, John suggested "consistency". We started an improvisation and created a piece with a strong rhythmic focus, with me adding some koauau over the top with John. Rachael, the assisting OT also added some koauau as she had got to a point where she was able to achieve this. John was particularly focused on rhythm, and as we played, other people around the ward seemed to look in and notice us, as if we were changing the feeling in the space.

Afterwards I asked each person how it felt... it was a quiet group by this stage. But Maggie and Rachael both acknowledged finding it difficult to stay consistent. I framed this as a positive thing as it allowed us to develop and change our playing. I talked about our abilities as players to tune in to each other's playing and how 'mistakes' became opportunities. After this I asked what people wanted to do, and no one said anything, but it didn't seem like people wanted to leave. At this point Lily came back into the group and began picking up instruments, I gave her a small bone koauau to try as it makes a sound quite easily, and she produced an eerie high tone. I showed Maggie this too, and the two of them worked trying several different instruments. This allowed me to have some time to work with John, I gave him the bone koauau again and sat with him as he worked on his breathing, whistling through it repeatedly. I remembered how last time John had gotten the koauau slowly... not all at once like some clients do. I got a koauau in a similar pitch range and played along side him, trying to communicate support through the music. Then together we heard his koauau producing a breathy note, I advised him to whistle to the same pitch and then he produced a loud tone, lifting his eyes to meet mine as he did. I invited the others with body language to join in with his playing and we improvised together with Lily on the bone koauau, Maggie on tumutumu, Rachael on porotiti and me and John on koauau. It was a beautiful moment where we were able to support John's music and his tenacity - part of the proverb that he had chosen.

At the end I acknowledged his tenacity and perseverance, and Maggie found a whakatauki that matched John's efforts about the value of perseverance which she gave to him, another beautiful moment acknowledging the feelings of whanaungatanga within what can be a difficult space. We ended the group here and I thanked everyone for coming. People 
asked if they could keep their whakatauki and I said they were welcome to. As I packed up, John stayed on to talk. He talked about struggling to get the koauau again... I talked about the value of perseverance over innate skill which he smiled at.

As I left, Roimata requested a whakatauki as well and received one about more people needing you as you grow stronger, which she attributed to her relationship with her daughter. 


\section{Appendix Three: Cycle One Nvivo coding example}

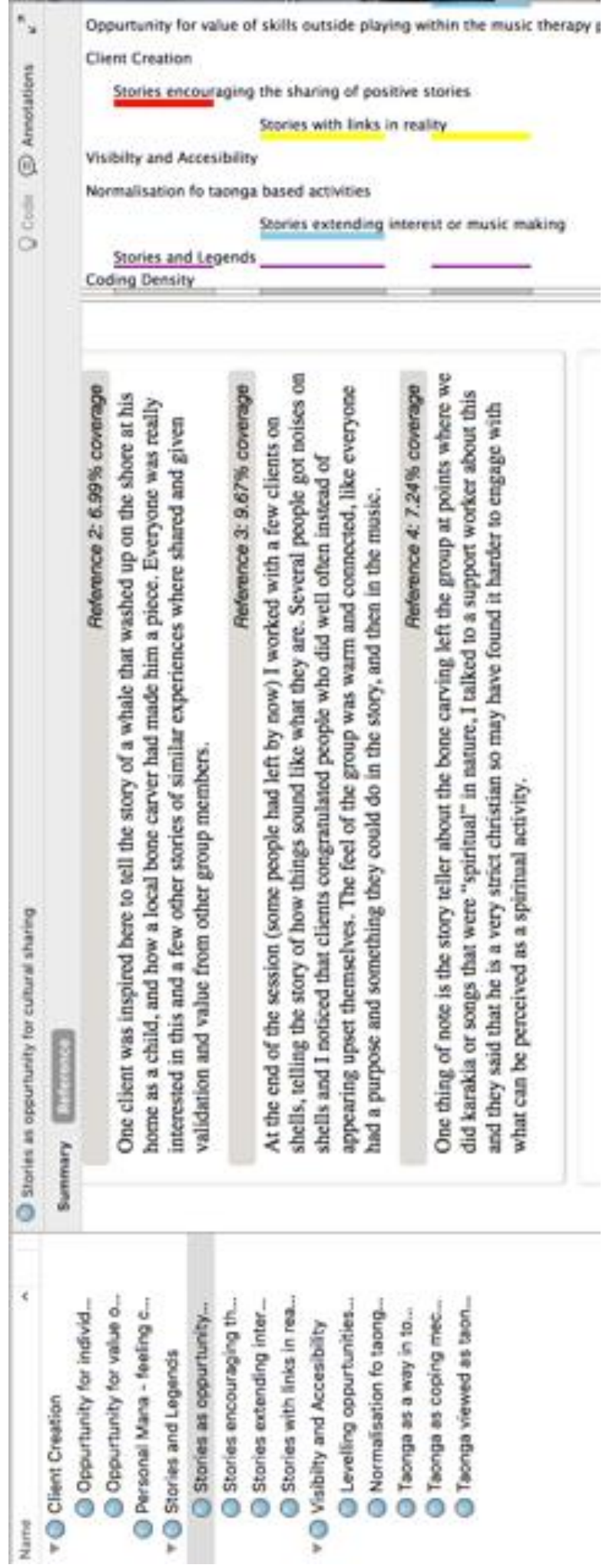




\section{Appendix Four: Example Diagram of Top Code with Sub Codes}

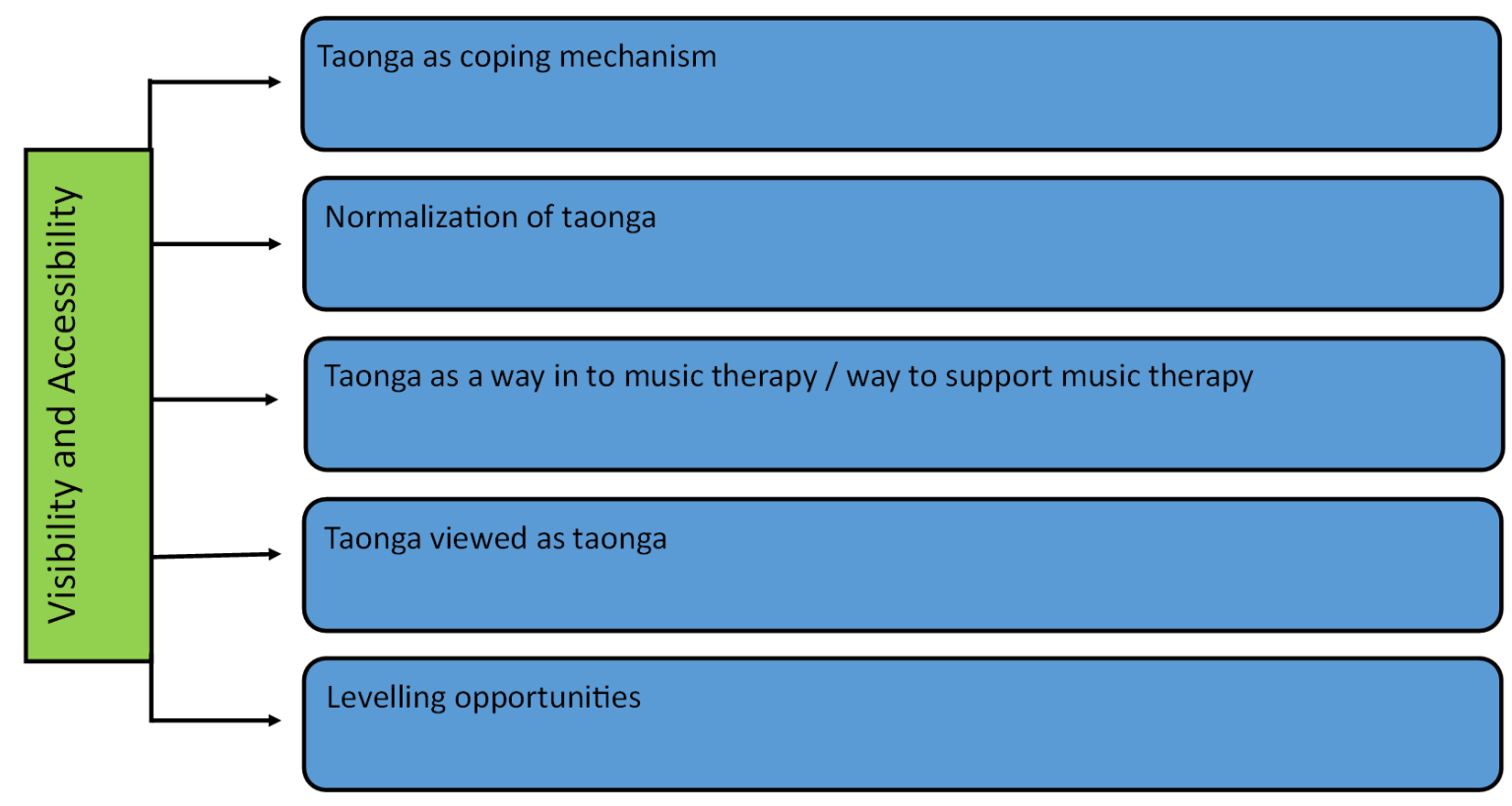

